\title{
Strongly Enhanced Piezoelectric Response in Lead Zirconate Titanate Films with Vertically Aligned Columnar Grains
}

\author{
Minh D. Nguyen, ${ }^{*}, \dagger, \ddagger \_$Evert P. Houwman, ${ }^{\dagger}$ Matthijn Dekkers, ${ }^{\ddagger}$ and Guus Rijnders ${ }^{\dagger}$ \\ ${ }^{\dagger}$ MESA+ Institute for Nanotechnology, University of Twente, P.O. Box 217, Enschede 7500AE, The Netherlands \\ ${ }^{\ddagger}$ Solmates B.V., Drienerlolaan 5, Enschede 7522NB, The Netherlands \\ ${ }^{\S}$ International Training Institute for Materials Science (ITIMS), Hanoi University of Science and Technology, Hanoi 10000, Vietnam \\ Supporting Information
}

ABSTRACT: $\mathrm{Pb}\left(\mathrm{Zr}_{0.52} \mathrm{Ti}_{0.48}\right) \mathrm{O}_{3}$ (PZT) films with (001) orientation were deposited on $\mathrm{Pt}(111) / \mathrm{Ti} / \mathrm{SiO}_{2} / \mathrm{Si}(100)$ substrates using pulsed laser deposition. Variation of the laser pulse rate during the deposition of the PZT films was found to play a key role in the control of the microstructure and to change strongly the piezoelectric response of the thin film. The film deposited at low pulse rate has a denser columnar microstructure, which improves the transverse piezoelectric coefficient $\left(d_{31 \mathrm{f}}\right)$ and ferroelectric remanent polarization $\left(P_{\mathrm{r}}\right)$, whereas the less densely packed columnar grains in the film deposited at high pulse rates give rise to a significantly higher longitudinal piezoelectric coefficient $\left(d_{33 \mathrm{f}}\right)$ value. The effect of film thickness on the ferroelectric and piezoelectric properties of the PZT films was also investigated. With increasing film thickness, the grain column diameter gradually increases, and also the average $P_{\mathrm{r}}$ and $d_{33 \mathrm{f}}$ values become larger. The largest piezoelectric coefficient of $d_{33 \mathrm{f}}=408 \mathrm{pm} \mathrm{V}^{-1}$ was found for a $4-\mu \mathrm{m}$ film thickness. From a series of films in the thickness range $0.5-5 \mu \mathrm{m}$, the $z$-position dependence of the piezoelectric coefficient could be deduced. A local maximum value of $600 \mathrm{pm} \mathrm{V}^{-1}$ was deduced in the 3.5-4.5 $\mu \mathrm{m}$ section of the thickest films. The dependence of the film properties on film thickness is attributed to the decreasing effect of the clamping constraint imposed by the substrate and the increasing spatial separation between the grains with increasing film thickness.

KEYWORDS: pulsed laser deposition, piezoelectric response, PZT film, microstructure, vertically aligned columnar growth

\section{INTRODUCTION}

Microelectromechanical systems (MEMS) actuators driven by lead zirconate titanate at the morphotropic phase boundary (MPB), $\mathrm{Pb}\left(\mathrm{Zr}_{0.52} \mathrm{Ti}_{0.48}\right) \mathrm{O}_{3}$ (abbreviated as PZT), have received wide attention recently because they could potentially outperform other MEMS actuators due to the remarkable high ferroelectric polarization and piezoelectric coefficients of PZT. $^{1-5}$ For the integration of PZT-based materials into MEMS, these should be prepared in thin film form. Therefore, the properties of PZT thin films are critical to the quality and reliability of MEMS devices. For most MEMS device applications, such as vibration energy harvesters, micropumps, microcantilever-based mass sensors, and ultrasonic transducers for medical and sonar applications, the transverse piezoelectric coefficient $\left(e_{31}\right.$ or $\left.d_{31}\right)$ is the most important factor to be considered. For specific applications, however, such as a nanocontrol system for the control of optical cavities, a high longitudinal piezoelectric coefficient $\left(d_{33}\right)$ is required to obtain a large piezoelectric, piston-like deformation in the PZT film actuators.

In recent years, there has been substantial progress in the optimization of piezoelectric PZT films. In most cases, the obtained effective $d_{33 \mathrm{f}}$ values of the films $\left(\sim 100-120 \mathrm{pm} \mathrm{V}^{-1}\right)$ are much lower than of the respective bulk PZT ceramics $\left(d_{33}=\right.$ $\left.223 \mathrm{pm} \mathrm{V}^{-1}\right){ }^{6}$ This difference was explained by the substrateinduced clamping of the thin film. ${ }^{7}$ Haun et al. ${ }^{8}$ analyzed the experimental data in the framework of the Landau-Devonshire phenomenological model and obtained values for the parameters that are fundamental to the piezoelectric effect. From this, a $d_{33}$ value of $327 \mathrm{pm} \mathrm{V}^{-1}$ was obtained for single domain, single crystals of PZT at the MPB. When comparing experimental results obtained for a different configuration (for example, for a clamped thin film) with theory, one may consider the value given by Haun et al. ${ }^{8}$ to be the intrinsic value of this composition. Several authors have analyzed theoretically and experimentally the dependence of the piezoelectric properties on the crystal orientation in clamped thin films. ${ }^{9-11}$ However, note that the theoretical results apply to a single domain structure only. The contribution of domain walls, grain size, and polarization rotation to the piezoelectric response, piezoelectric hysteresis has been reviewed extensively by Damjanovic and co-workers. ${ }^{12,13}$

Received: December 22, 2016

Accepted: March 1, 2017

Published: March 1, 2017 
It is well-known that extrinsic effects arising from domain formation, as occurs often in clamped films and domain wall motion under the influence of applied mechanical stress or electrical fields, can contribute significantly to the net piezoelectric effect. The effect of clamping on the ferroelectric, piezoelectric, and dielectric properties of a thin PZT film has been investigated theoretically by Pertsev and co-workers ${ }^{14-16}$ within the Landau-Devonshire phenomenological model, both for a single domain and for a polydomain structure. Recently, these theoretical studies were revisited, using different boundary conditions for the interaction between different domains. ${ }^{17}$ A detailed comparison of this model with experimental data for a $800 \mathrm{~nm}$-thick PZT(40/60) epitaxial film enabled a decomposition of the measured piezoelectric coefficient into separate extrinsic and intrinsic contributions. ${ }^{18}$

The effect of clamping on the piezoelectric properties has also been investigated experimentally and theoretically by changing the aspect ratio $(t / d)$ of the thickness $(t)$ of the piezoelectric thin film capacitor stack to the diameter $(d)$ of the substrate-film interface. ${ }^{19-23}$ Nagarajan et al. ${ }^{19}$ and Buhlmann et $\mathrm{al}^{23}$ found strongly enhanced piezoelectric properties for PZT structures with $t / d \geq 1$. In the first paper, this was explained in terms of thermodynamic theory for a unclamped single domain film, while in the second it was proposed that this enhancement is mostly due to a change in the domain configuration from a mixed $c / a$ domain configuration induced by the substrate clamping-induced thermal strain for a continuous film to a configuration consisting of mainly $c$ domains. The latter explanation is much in line with the polydomain Landau-Devonshire modeling. ${ }^{14,16,17}$ Buhlmann et al. $^{23}$ also attributed the reduced piezoelectric activity found by Ganpule et al. ${ }^{21}$ to damage to the crystal structure caused by the FIB processing used to pattern the capacitors and to the polycrystalline nature of the material, possibly both causing enhanced domain wall pinning. Finite element modeling (FEM) of $200 \mathrm{~nm}$ thick $\mathrm{PbZr}_{0.5} \mathrm{Ti}_{0.5} \mathrm{O}_{3}$ capacitor with varying aspect ratio ( 0.01 to 1 ) structures (patterned by FIB milling) showed that the capacitor surface displacement depends on three factors: the intrinsic piezostrain, elastic strain in the film due to the substrate clamping, and local nonuniform deformation of the substrate. ${ }^{24}$ The latter two strongly depend on the aspect ratio of the capacitor structure and the elastic properties of the substrate. We note that such FEM modeling is very suitable to model the mechanical interaction between substrate and the (nanostructured) piezo capacitor, but cannot take into account the effect of a changing strain state on the domain-structure in the capacitor and with that on the change of the piezoelectric coefficient.

In the latter papers, single, high aspect ratio capacitor structures have been fabricated by various pattern techniques. Here, we describe the fabrication and analysis of films, which consist of mechanically partly disconnected, (001) orientation and columnar grains with a diameter of about $100 \mathrm{~nm}$. With respect to the piezoelectric properties, we therefore assume that our large area $\left(300 \times 300 \mu \mathrm{m}^{2}\right)$ capacitor structures made of such films are composed of a dense parallel array of high aspect ratio $\left(t / d_{\text {col }}\right.$ varies between 9 and 22) piezoelectric capacitors with common electrodes. Because of the large area, the capacitors are largely declamped from the substrate, but are still partly clamped by the adjacent columns. We interpret the obtained ferroelectric and piezoelectric properties within this description.
Next to the effect of declamping in columnar piezoelectric structures, one also observes a dependence of the effective piezoelectric coefficient of the film on the film thickness. Recently, a strong thickness dependence of $d_{33}$ in PZT films grown on $\mathrm{SrTiO}_{3} / \mathrm{Si}$ was observed by Kim et al. ${ }^{25}$ A very high $d_{33}$ value up to $330 \mathrm{pm} \mathrm{V}^{-1}$ for a $4-\mu \mathrm{m}$-thick film was measured. This high value may have been due to the measurement method (piezoelectric force microscopy) used and the cracking of the thick films. A recent theoretical study using phase-field simulation on bulk single crystal PZT with near MPB compositions with a polydomain structure suggested that a $d_{33}$ value of $520 \mathrm{pm} \mathrm{V}^{-1}$ is possible for $\mathrm{Pb}\left(\mathrm{Zr}_{0.52} \mathrm{Ti}_{0.48}\right) \mathrm{O}_{3}$ and even $720 \mathrm{pm} \mathrm{V}^{-1}$ for $\mathrm{Pb}\left(\mathrm{Zr}_{0.53} \mathrm{Ti}_{0.47}\right) \mathrm{O}_{3}{ }^{26}$ This high value was ascribed to the large extrinsic effect of the easy domain switching between the many possible polarization states in this material arising from a mixture of tetragonal and rhombohedral domains.

For the deposition of the piezoelectric PZT films, several deposition techniques along both chemical and physical routes have been used. The physical methods include sputter deposition, ${ }^{27-29}$ pulsed laser deposition (PLD), ${ }^{30-33}$ molecular beam epitaxy (MBE), ${ }^{34}$ and evaporation. ${ }^{35,36}$ The chemical methods are metal-organic chemical vapor deposition, ${ }^{37,38}$ plasma enhanced chemical vapor deposition, ${ }^{39,40}$ and sol-gel processing. ${ }^{41-45}$ Each deposition technique has its intrinsic advantages and disadvantages. PLD has been demonstrated to be a versatile method for the fabrication of high-quality thin films. ${ }^{46}$ The main advantage of PLD is the possibility to transfer a stoichiometrically multicomponent target material, especially containing volatile components such as lead, to the layer. Moreover, PLD is a powerful method that allows a thicker film to be fabricated in a short time due to the high deposition rate and the possibility to incorporate the process directly into a Siproduction line, ${ }^{47,48}$ for example, in MEMS.

In general, PLD is a relatively simple experimental deposition technique. By controlling a few PLD deposition parameters, such as the laser energy density, laser spot size, substrate deposition temperature, oxygen deposition pressure, and target-substrate distance, PZT films with the desired microstructure and properties can be obtained. ${ }^{46,49-53}$ Further, in general, a smooth film surface may be obtained by varying the laser pulse rate while keeping the amount of material deposited per shot constant. ${ }^{54}$ A slow deposition rate at fixed laser pulse energy density means that the nuclei have more time to ripen and the film may evolve into a smooth surface with large flat areas. ${ }^{50}$ However, there is no study on the effect of the laser pulse frequency on the PLD growth and properties of PZT films. Guan et al. ${ }^{50}$ used a Monte Carlo computational model to study the influence of the laser pulse rate on island density and film morphology in the initial phase of PLD film growth. The computational results indicated that more and smaller size islands are formed at a higher pulse rate and the reduced island size can enhance the diffusion of adatoms, resulting in a smoother film surface. On the other hand, a short duration of intense deposition results in a high supersaturation, which also affects the nucleation and growth processes. ${ }^{55}$

The subject of the present study is the deposition of PZT films on platinized silicon substrates $\left(\mathrm{Pt} / \mathrm{Ti} / \mathrm{SiO}_{2} / \mathrm{Si}\right.$ or short $\mathrm{Pt} / \mathrm{Si}$ ) by controlling the laser pulse rate to change and maximize the longitudinal piezoelectric response of films with different thicknesses. The other optimized deposition parameters are as given in ref 56 . The $\mathrm{Pt} / \mathrm{Si}$ substrate is chosen here because it has found widespread use in the industrial 
production of microsystems employing PZT. The main result is that with increasing laser pulse rate and film thickness, the (average) $d_{33 \mathrm{f}}$ value is increased strongly up to $408 \mathrm{pm} \mathrm{V}^{-1}$ for a $4-\mu \mathrm{m}$-thick film, deposited at $50 \mathrm{~Hz}$. The local piezoelectric coefficient $\left(d_{33}(z)\right)$ reaches even a value of $600 \mathrm{pm} \mathrm{V}^{-1}$ in the 3-4 $\mu \mathrm{m}$ section of film with thicknesses of $4 \mu \mathrm{m}$ or more.

\section{EXPERIMENTAL SECTION}

Film Deposition. The PZT films were deposited on (111)Pt/Ti/ $\mathrm{SiO}_{2} / \mathrm{Si}(\mathrm{Pt} / \mathrm{Si})$ using pulsed laser deposition (PLD) with a $\mathrm{KrF}$ excimer laser (Lambda Physik, wavelength $248 \mathrm{~nm}$, pulse duration 20 ns). $125 \mathrm{~nm}$-thick Pt bottom electrodes and $15 \mathrm{~nm}$-thick Ti adhesive layers were deposited at room temperature by DC magnetron sputtering on a $500 \mathrm{~nm}$-thick $\mathrm{SiO}_{2}$ layer formed through wet oxidation at $1100{ }^{\circ} \mathrm{C}$. To prevent the formation of pyrochlore phases at the interface between the PZT film and the Pt bottom electrode, a thin nucleation layer of $\mathrm{LaNiO}_{3}$ (LNO, $10 \mathrm{~nm}$, using PLD) was inserted between the Pt and the PZT (see Figure S1). The growth conditions for the LNO layer are given in ref 56. The optimized growth conditions for the PZT layers were as follows: substrate temperature of $600{ }^{\circ} \mathrm{C}$; target-substrate distance $60 \mathrm{~mm}$; laser spot size $3.0 \mathrm{~mm}^{2}$; laser power density $2.5 \mathrm{~J} \mathrm{~cm}^{-2}$; and a pressure of $0.1 \mathrm{mbar}_{2}$ during deposition. ${ }^{56}$ To investigate the effect of the pulse rate $(10-50 \mathrm{~Hz})$, PZT films with a thickness of about $2 \mu \mathrm{m}$ were deposited, and for the study on the effect of film thickness, the PZT films with thickness in the range of $0.5-5.0 \mu \mathrm{m}$ were deposited at $50 \mathrm{~Hz}$. After deposition, the films were cooled to room temperature with a ramp rate of $10^{\circ} \mathrm{C}$ $\min ^{-1}$ in a 100 mbar $\mathrm{O}_{2}$ atmosphere. Top electrodes $(\mathrm{Pt}, 125 \mathrm{~nm}$ ) were deposited on PZT films at room temperature by DC magnetron sputtering.

Analysis and Characterization. Crystallographic properties of the PZT films were analyzed with X-ray $\theta-2 \theta$ scans (XRD) using a PANalytical X'Pert X-ray Diffraction system. Film surface and microstructure were investigated using atomic force microscopy (AFM, Bruker Dimension ICON) and high-resolution scanning electron microscopy (HRSEM, Zeiss 1550). For the electrical measurements, $300 \times 300 \mu \mathrm{m}^{2}$ capacitors were patterned with a standard photolithography process and structured by argon-beam etching of the top $\mathrm{Pt}$ electrodes and wet-etching ( $\mathrm{HF}-\mathrm{HCl}$ solution) of the PZT films to expose the bottom electrodes.

The polarization hysteresis $(P-E)$ loop measurements were performed with the ferroelectric mode of the aixACCT TF-2000 Analyzer using a triangular AC-electric field of $\pm 200 \mathrm{kV} \mathrm{cm}^{-1}$ at $1 \mathrm{kHz}$ scanning frequency. All measurements were performed after bipolar cycling the devices a few times. The hysteresis loops did not change after the first few cycles. The small-signal $d_{33 f}$ measurements (index SS) of the piezoelectric film capacitors were measured with a double beam laser interferometer (aixDBLI) apparatus that eliminates the influence of the substrate bending, ${ }^{57,58}$ using a lock-in technique with a DC driving electrical field in the range $\pm 200 \mathrm{kV} \mathrm{cm}^{-1}$, and an AC peak-peak field amplitude of $5 \mathrm{kV} \mathrm{cm}^{-1}$ and $1 \mathrm{kHz}$ frequency. The coercive field of the films is typically $30-40 \mathrm{kV} \mathrm{cm}^{-1}$. It requires polishing of the back side of the substrate to ensure a reflecting surface for the second laser beam. The resolution of the aixDBLI is better than $1 \mathrm{pm} \mathrm{V}^{-1}$; therefore, the experimental accuracy is better than $1 \%$, as the measured $\mathrm{AC}$ deflections in this measurement mode are in the sub$1 \mathrm{~nm}$ range for our devices. The aixDBLI measurement is still sensitive to the effect of the indentation of the substrate underneath the capacitor, due to the clamping with the piezoelectric film and the finite elasticity of the substrate. To estimate the effect of the aspect ratio on the clamping by the substrate and thus on the measured $d_{33 \text { f }}$ we performed FEM analysis on circular capacitor structures with different structure thickness $(t)$ and diameter $(w)$ on Si, similar to that in ref 24 . These show that for $t / w>10$, the observed $d_{33 f}$ is that of an unclamped sample, whereas for $t / w<0.2$, it is close to that of a clamped, continuous piezoelectric film, with the crossover between the two regimes for $t / w \approx 1$. These results are very much comparable to those in ref 24. Unipolar and bipolar large-signal (index LS) displacement $(\Delta z-E)$ hysteresis loops were measured at a scan frequency of $100 \mathrm{~Hz}$ up to $\pm 200 \mathrm{kV} \mathrm{cm}^{-1}$. Loops were averaged over 100 cycles. From these loops, the strain $(S-E)$ and large-signal piezoelectric $\left(d_{33 \mathrm{f}}^{\mathrm{LS}}-E\right)$ hysteresis loops were calculated.

In addition, we measured the tip displacement of $400 \times 100 \times 10$ in $\mu \mathrm{m} \mathrm{Si}$ cantilevers to determine an thickness averaged value for the product of the (in-plane value of the) Young's modulus $E_{\mathrm{p}}$ and the piezoelectric coefficient, $\left\langle E_{\mathrm{p}}{ }^{\prime} d_{31 f}{ }^{\prime}\right\rangle$ (the prime indicates the modification involving the Poisson ratio $\nu$, due to the thickness/width aspect ratio of the cantilever; see the Supporting Information). For our piezoelectric layer, one expects that $E_{\mathrm{p}}, \nu$, and $d_{31 \mathrm{f}}^{\mathrm{SS}}$ vary over the thickness and also to be very different from those of dense films due to the columnar structure. In that case, the cantilever method does not allow the separation of these parameters. ${ }^{59}$ Nevertheless, a possible trend in the value of $\left\langle E_{\mathrm{p}}{ }^{\prime} d_{31 f^{\prime}}\right\rangle$ with changing thickness will reflect thickness-dependent properties. The cantilevers were produced from a Silicon-On-Insulator (SOI) wafer (see the Supporting Information), and the tip deflection was measured with a scanning laser Doppler vibrometer (LDV), driven by the piezoelectric stack at an ACamplitude of $\pm 30 \mathrm{kV} \mathrm{cm}^{-1}$ (at a DC offset voltage of $30 \mathrm{kV} \mathrm{cm}^{-1}$ ) and $8 \mathrm{kHz}$ frequency (see Figure S7). The process for fabricating piezoelectric driven $\mathrm{Si}$ cantilevers has been described in a previous paper $^{60}$ and is depicted schematically in Figure S6. We note here that one cannot directly compare the obtained values of the columnar films in this report with those from dense films, for which the elastic properties are well-known.

\section{RESULTS AND DISCUSSION}

Effect of Laser Pulse Rate. Typical X-ray diffraction (XRD) patterns of $2-\mu \mathrm{m}$-thick PZT films with Pt bottom and top electrodes, deposited on $\mathrm{Pt}(111) / \mathrm{Ti} / \mathrm{SiO}_{2} / \mathrm{Si}(100)$ (platinized $\mathrm{Si}$ or short $\mathrm{Pt} / \mathrm{Si}$ ) substrates with a $10 \mathrm{~nm}$-thick $\mathrm{LaNiO}_{3}$ buffer/nucleation layer on top of the Pt bottom electrode, using different laser pulse rates, are shown in Figure 1. The diffraction

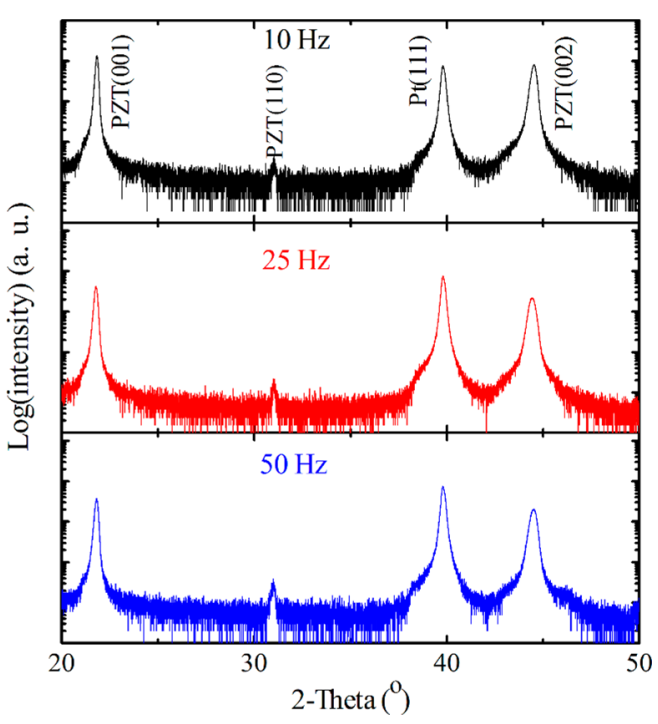

Figure 1. XRD $\theta-2 \theta$ scans of $2-\mu \mathrm{m}$-thick PZT films deposited on Pt/ $\mathrm{Si}$ with 10,25 , and $50 \mathrm{~Hz}$ laser pulse rates.

patterns indicate a well-crystallized perovskite phase with predominantly (001)-oriented growth. The (110) fraction is in the few promille range. No other phases, such as the pyrochlore phase, were detected. There is no shift of the (001) peak position; thus the out-of-plane lattice parameter is not affected by the pulse rate. The out-of-plane lattice parameter is $a_{\text {oop }}=4.074 \AA$, and no peak splitting is observed. The single value of $a_{\text {oop }}$ is between the lattice parameters of the tetragonal unit cell of the MPB composition reported by Noheda et al. ${ }^{61}$ 
This may indicate that we are measuring an effective value, arising from a domain fraction weighted average of the out-ofplane lattice parameters in $c$ and $a$ nanometer-sized domains. Such averaging occurs when the domain sizes are less than the coherence length of the X-ray beam. ${ }^{62}$ The adaptive phase theory in ref 63 describes the effective lattice parameter changes under a changing stress state. It appears that within this model effective lattice parameters are very small, even for $10-20 \%$ changes in the $c$-domain fraction. Alternatively, one could assume that the lattice parameter of this MPB composition is that of a rhombohedral unit cell, which is only marginally distorted under changing strain. However, this explanation is not in accordance with the tetragonal unit cell reported by Noheda et al. ${ }^{61}$

The effect of the laser pulse rate on the surface and microstructure of PZT films is shown in Figure 2. The AFM

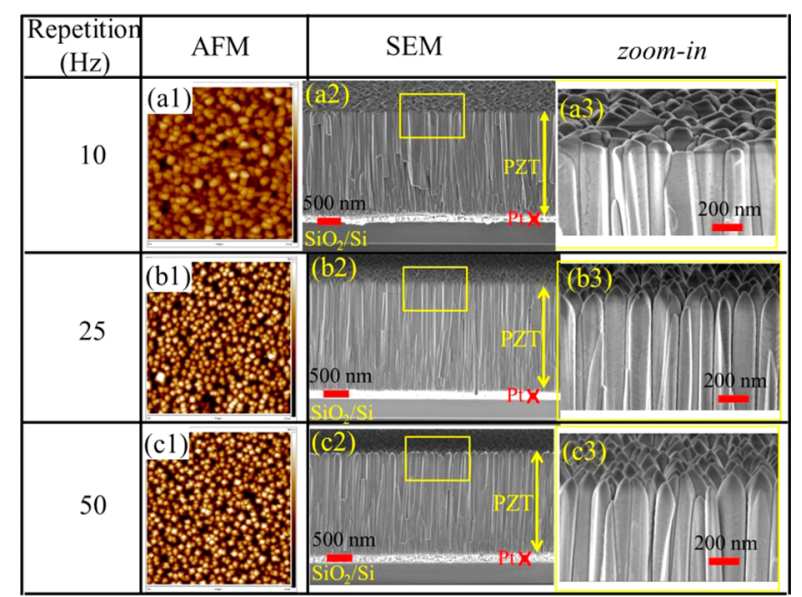

Figure 2. $(\mathrm{a} 1-\mathrm{c} 1)$ AFM $\left(3 \times 3-\mu \mathrm{m}^{2}\right)$ and $(\mathrm{a} 2-\mathrm{c} 2)$ cross-sectional SEM images of $2-\mu \mathrm{m}$-thick PZT films deposited on $\mathrm{Pt} / \mathrm{Si}$ at various laser pulse rates. SEM magnifications of the top surface of the films (indicated by the square in $\mathrm{a} 2-\mathrm{c} 2$ ) are given in $\mathrm{a} 3-\mathrm{c} 3$.

surface scans in Figure 2, panels a1, b1, and c1, indicate an increased surface roughness and decreasing grain size with increasing pulse rate. Root-mean-square (RMS) roughness values were calculated from the AFM measurements and are given in Table 1 . The average surface roughness approximately doubles when the pulse rate is increased from 10 to $25 \mathrm{~Hz}$ and slightly increases further for $50 \mathrm{~Hz}$. AFM line scans (see Figure S2) show that the peak-to-peak roughness is about $45 \mathrm{~nm}$ for a film deposited at $10 \mathrm{~Hz}$, while that of a film at $50 \mathrm{~Hz}$ is as large as $138 \mathrm{~nm}$, indicating that a smoother film is obtained for a lower pulse rate.
The cross-sectional SEM images in Figure 2, panels a2, b2, and $\mathrm{c} 2$, show columnar growth with relatively flat top shaped grains extending through the whole thickness of the film deposited at $10 \mathrm{~Hz}$. At higher laser pulse rate, grains with a tapered shape and a pyramid-like top are obtained. Further, the columnar grains are less closely packed with increasing laser pulse rate (see Figure 2, panels a3, b3, and c3). From the increase in growth rate with laser rate (see Table 1), it is concluded that the density of the film decreases with increasing pulse rate, assuming that the same amount of material is ablated and deposited per shot. The XRD measurements indicate that the crystalline structure and thus the density in the grain interior are the same for these samples; thus the apparent increased growth rate must reflect an increase of the void fraction in the film. In the Supporting Information, it is deduced that the void fraction of the $2-\mu \mathrm{m}$-thick PZT film deposited at $50 \mathrm{~Hz}$ film is as high as $6.9 \%$.

Figure S3 shows cross sections of the complete $2-\mu$ m-thick film deposited at 10 and $50 \mathrm{~Hz}$, respectively, as well as close-up views at the bottom-electrode interface and the top of these films. These images show that the nucleation of the initial PZT growth layer has a significant effect on the growth of the grains. For the $50 \mathrm{~Hz}$ film, the average column diameter increases from about $36 \mathrm{~nm}$ at the bottom (see Figure S3e) to $145 \mathrm{~nm}$ at the top (see Figure S3f), while for the $10 \mathrm{~Hz}$ deposited film, it changes from $60 \mathrm{~nm}$ (see Figure S3b) to $180 \mathrm{~nm}$ (see Figure S3c) (see also Table 1). Clearly, with increasing laser rate the nucleation density increases, so that the initial grain diameter remains small (as was suggested by Guan et al. ${ }^{50}$ ), but also the final diameter is smaller for higher pulse rate. The observed columnar structure is reminiscent of Thornton's StructureZone Model. ${ }^{64}$ Within that model, the columnar growth is ascribed to low adatom mobility. The PLD deposition temperature is about 0.45 times the melting temperature of a typical perovskite, while the $0.1 \mathrm{mbar}$ oxygen pressure corresponds to the very high pressure range of the Zone Model. For these conditions, in Thornton's Structure Zone Model the film grows with tapered crystallites separated by voids rather than by grain boundaries. In this regime, the film has poor lateral strength and is underdense, although the density of the crystallites is near the bulk value. It was argued that the voided structure arises from the low adatom mobility due to the high pressure. In our case, the deposition pressure and temperature are maintained the same for all depositions, but it is the laser rate that is varied. In a few aspects, the PLD process is quite different from the sputter deposition of a metal target, for which the Zone Model was developed. First, here PLD is performed from a multicomponent target, resulting in a complex metal oxide film, contrary to the single element metal target from which the Zone Model was derived. This seems to

\section{Table 1. Properties of $2-\mu \mathrm{m}$-Thick PZT Films Deposited at Various Laser Pulse Frequencies}

\begin{tabular}{|c|c|c|c|c|c|c|c|c|c|}
\hline $\begin{array}{l}\text { laser freq } \\
(\mathrm{Hz})\end{array}$ & $\begin{array}{c}\text { growth rate } R(f) \\
(\mathrm{nm} / \text { pulse })\end{array}$ & $\begin{array}{l}\text { ave void } \\
\text { fraction }^{a}\end{array}$ & $\begin{array}{c}R_{\mathrm{pp}} / R_{\mathrm{rms}} \\
\text { roughness }(\mathrm{nm})\end{array}$ & $\begin{array}{l}\text { ave grain diameter } \\
d_{\text {col }}(\mathrm{nm})^{b}\end{array}$ & $\begin{array}{c}\text { aspect ratio } \\
t / d_{\mathrm{col}}\end{array}$ & $\left(\mu \mathrm{C} \mathrm{\textrm {cm } ^ { - 2 } ) ^ { c }}\right.$ & $\begin{array}{c}d_{33 \mathrm{f}}^{\mathrm{SS}} \\
\left(\mathrm{pm} \mathrm{\textrm {V } ^ { - 1 }}\right)\end{array}$ & $\begin{array}{c}E_{\mathrm{p}}^{\prime} d_{31 \mathrm{f}}^{\prime} \\
\left(\mathrm{GPa} \mathrm{pm} \mathrm{V} \mathrm{V}^{-1}\right)^{d}\end{array}$ & $\begin{array}{c}\text { rel. dielec. } \\
\text { constant } \varepsilon_{\mathrm{r}}^{S \mathrm{~S}}(0)\end{array}$ \\
\hline 10 & 0.0293 & $1.6 \%$ & $45 / 15.2$ & $60 / 180$ & 11.1 & 39.3 & 192 & -13620 & 1020 \\
\hline 25 & 0.0315 & $5.8 \%$ & $124 / 31.8$ & $42 / 150$ & 13.3 & 36.9 & 266 & -11123 & 956 \\
\hline 50 & 0.0325 & $6.9 \%$ & $138 / 35.0$ & $36 / 145$ & 13.8 & 35.1 & 305 & -9761 & 910 \\
\hline
\end{tabular}

${ }^{a}$ As compared to a fictive film deposited at $0 \mathrm{~Hz}$ (see the Supporting Information). ${ }^{b}$ At the bottom/at the top, of the $2 \mu \mathrm{m}$ layer. For the aspect ratio, the diameter at the top of the film is used. ${ }^{c}$ Obtained from the $P$-axis crossing of the tangent to the $P-E$ loop at high fields. ${ }^{d}$ The curvature of a piezoelectric driven cantilever also depends on the Young's modulus $E$ of the piezoelectric layer. This parameter is expected also to change with the void fraction. The curvature of the cantilever depends on the average product $E_{\mathrm{p}} d_{31 \text { f }}$, which is given here to show the decreasing trend due to the changing pulse rate (see the Supporting Information). The corresponding value for a monodomain single crystal is $-13620 \mathrm{GPa}^{\mathrm{pm}} \mathrm{V}^{-1}$. 
(a)

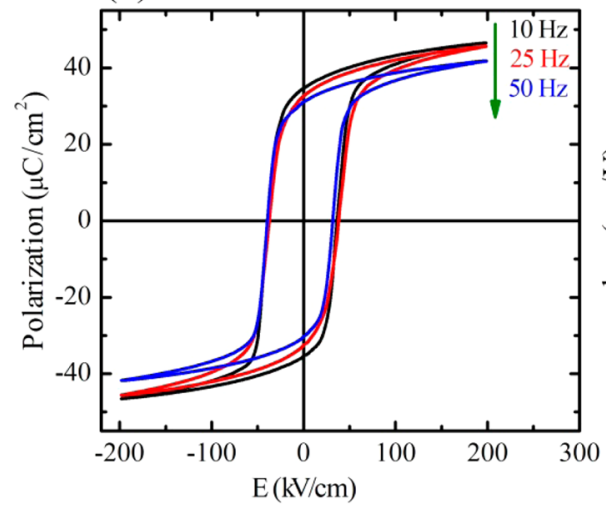

(b)

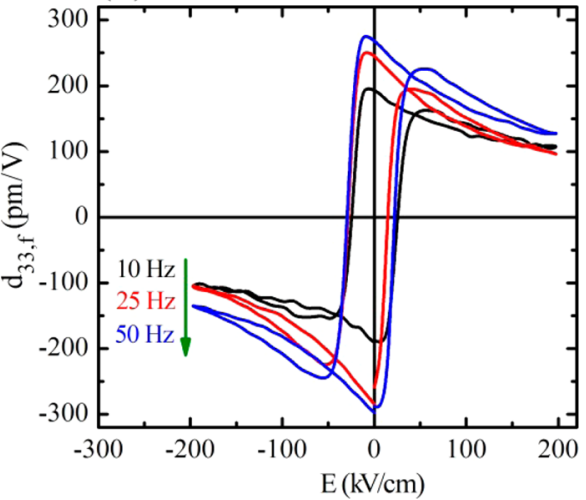

Figure 3. (a) $P-E$ and (b) $d_{33 f}-E$ loops of $2-\mu \mathrm{m}$-thick PZT films deposited on $\mathrm{Pt} / \mathrm{Si}$ at various laser pulse rates.

be of no significant consequence for the developed structure. More importantly, the Zone Model was developed for continuous sputter deposition, whereas in PLD the deposition is in bursts of typically $10-40 \mu \mathrm{s}$. This creates a very high supersaturation with a temporal deposition rate of 2500 perovskite unit cells per second during the pulse (irrespective of the pulse rate), as compared to only 4 unit cells per second for sputter deposition (at $1000 \AA \mathrm{min}^{-1}$ ), creating a very high nucleation density on the substrate and momentarily very low adatom mobility during the film growth. ${ }^{65}$ The adatom density rapidly drops after the pulse, and the mobility increases accordingly until the next pulse arrives. With increasing laser pulse rate, the available diffusion time before another deposition pulse arrives decreases from $100 \mathrm{~ms}$ for the $10 \mathrm{~Hz}$ film to $20 \mathrm{~ms}$ for the $50 \mathrm{~Hz}$ film. Thus, it appears that the change in columnar structure with changing laser rate can be attributed to the change in available diffusion time, limiting the range of the mobile surface atoms. It also implies that the surface diffusion time is in the range of a few $10 \mathrm{~ms}$.

Figure 3 shows the room-temperature polarization hysteresis loop $(P-E)$ and the small-signal piezoelectric loop $\left(d_{33 f}-E\right)$ of PZT films measured up to $\pm 200 \mathrm{kV} \mathrm{cm}^{-1}$. The remanent $\left(P_{\mathrm{r}}\right)$ and spontaneous $\left(P_{\mathrm{s}}\right)$ polarizations decrease slightly with increasing laser rate, whereas the coercive field hardly changes. The changing $P_{s}$ hints toward a changing strain state. The increased $d_{33 \mathrm{f}}$ values are ascribed to increasing domain wall motion and polarization rotation in the less clamped films, ${ }^{66}$ deposited with higher laser pulse rate. With increasing laser pulse rate, $P_{\mathrm{s}}$ decreases slightly from 39.3 to $35.1 \mu \mathrm{C} \mathrm{cm}^{-2}$. The higher value at $10 \mathrm{~Hz}$ deposited film implies that the polarization vector is rotated in the out-of-plane direction due to compressive in-plane stress. This is surprising because the thermal stress after cooling from deposition temperature, arising from the difference in thermal expansion coefficients between substrate and film, is expected to give a small tensile stress. Hence, one must conclude that already during deposition the $10 \mathrm{~Hz}$ deposited film is grown in a compressed state, which is not fully relaxed during cooling. With increasing pulse rate, apparently the film already grows less compressively strained and is further relaxed upon cooling, so that the polarization rotates toward the in-plane direction. The reduced compressive strain is consistent with the increasing void fraction for higher pulse rates (Table 1 ).

The $d_{33 \mathrm{f}}$ value is significantly enhanced for higher pulse rate (Table 1). Note that the maximum $d_{33 \mathrm{f}}$ value of the PZT film deposited at $50 \mathrm{~Hz}\left(305 \mathrm{pm} \mathrm{V}^{-1}\right)$ is much larger than the value for bulk ceramics $\left(223 \mathrm{pm} \mathrm{V}^{-1}\right)$ given by Jaffe et al. ${ }^{6}$ and is close to the intrinsic (single crystal, single-domain) value ( 327 pm $\mathrm{V}^{-1}$ ) given by Haun et al. ${ }^{8}$ The increase of the $d_{33 \mathrm{f}}$ value with increasing pulse rate can be understood from the decreasing interconnection between the grains and therefore less effective clamping of the film.

The value of $\left\langle E_{\mathrm{p}}{ }^{\prime} d_{31 \mathrm{f}}{ }^{\prime}\right\rangle$, determined from cantilever bending for a cantilever with a $10 \mathrm{~Hz}$ deposited piezoelectric film, is equal to that expected for monodomain single crystal material, reflecting the high density of this film. With increasing pulse rate, $\left\langle E_{\mathrm{p}}{ }^{\prime} d_{31 \mathrm{f}}{ }^{\prime}\right\rangle$ decreases slightly with increasing pulse rate as one expects for a film in which the grains are less well interconnected so that in-plane piezoelectric stress can develop less well and the in-plane Young's modulus is reduced.

The small-signal zero-field relative dielectric constant $\left(\varepsilon_{\mathrm{r}}^{\mathrm{SS}}(0)\right)$, obtained from the capacitance-field $(C-E)$ curves, as shown in Figure S5a, is slightly larger for the denser film deposited at a lower pulse rate (Table 1$)$. The zero-field $\varepsilon_{\mathrm{r}}^{\mathrm{SS}}(0)$ values are about 2.5 times larger than that of the single crystal, single domain value $\varepsilon_{\mathrm{r}}^{\mathrm{SC}}(0)=382 .{ }^{8}$ We attribute this large difference to a large extrinsic contribution from domain wall motion to the permittivity. The high-field values (at $200 \mathrm{kV}$ $\mathrm{cm}^{-1}$ ) are close to $\varepsilon_{\mathrm{r}}^{\mathrm{SC}}(0)$.

Effect of PZT Film Thickness. To investigate the effect of the film thickness on the structural and electrical properties, samples with film thicknesses between $0.5-5.0 \mu \mathrm{m}$ have been prepared with the same pulse rate of $50 \mathrm{~Hz}$. Figure 4 shows the XRD patterns of these films. All films are crystallized in a pure perovskite phase with predominantly (001) orientation, and no evidence for secondary phase formation was found. The volume fraction of (110) oriented growth rapidly decreases with increasing film thickness from as much as a few percent for the thinnest film to about a promille for the thickest film. This indicates that with increasing film thickness, the (110)-oriented grains stop growing in length. Further on, we will see that with increasing thickness the grain diameter increases, and thus the space initially occupied by the (110)-oriented grains is expected to be filled with the increasing diameter of the (100)-oriented grains. There is no shift of the (ool) peaks for increasing film thickness, and thus no change in the out-of-plane lattice parameters.

The AFM and SEM micrographs of the surfaces and cross sections of PZT films, deposited at $50 \mathrm{~Hz}$ and as a function of film thickness, are shown in Figure 5. From the AFM surface micrographs, it is seen that the grain size and the average distance between the PZT grains appear to change with 


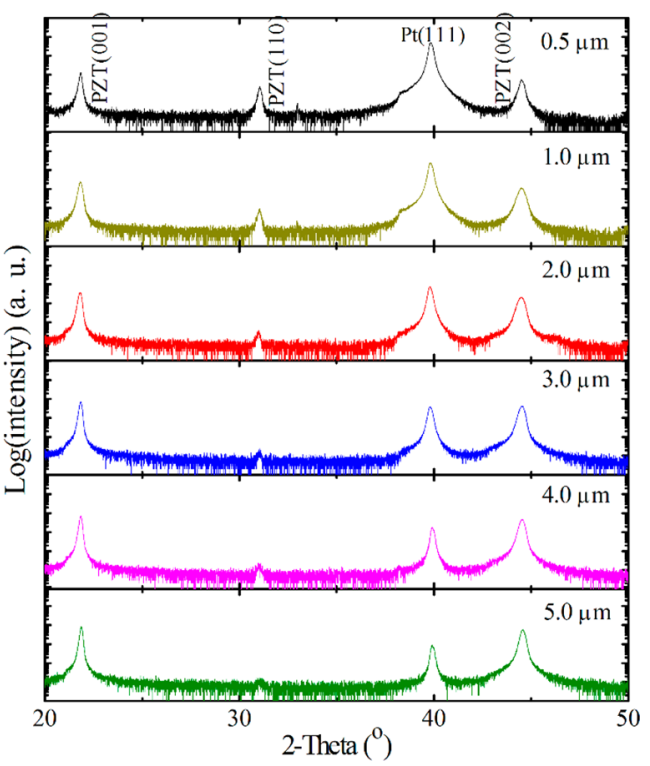

Figure 4. XRD $\theta-2 \theta$ scans of PZT films with various thicknesses deposited on $\mathrm{Pt} / \mathrm{Si}$ with a laser pulse rate of $50 \mathrm{~Hz}$.

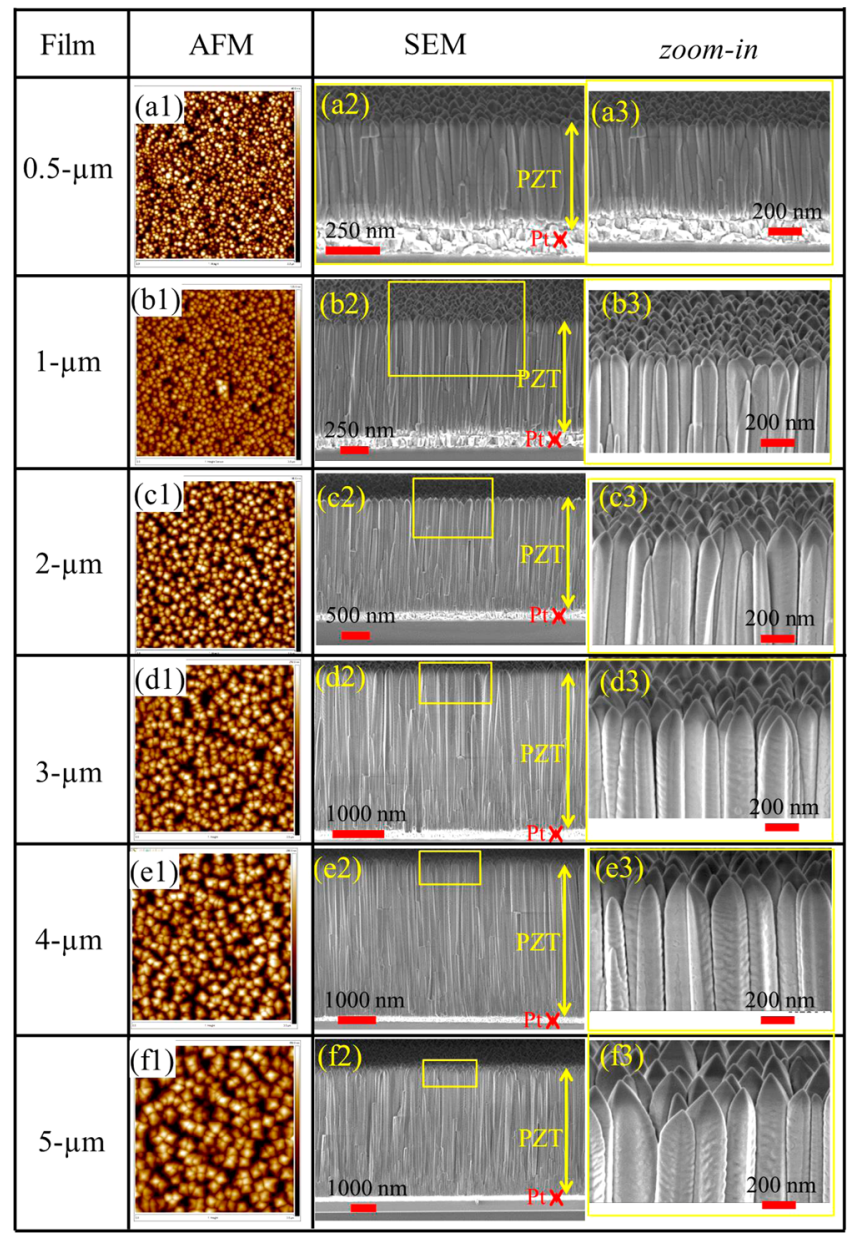

Figure 5. (a1-f1) AFM and (a2-f2) cross-sectional SEM (a2-f2) images of PZT films with thicknesses of $0.5-5 \mu \mathrm{m}$, deposited on $\mathrm{Pt} / \mathrm{Si}$ with a $50 \mathrm{~Hz}$ pulse rate. SEM magnifications of the top surface of the films (indicated by the square in a2-f2) are given in a3-f3.

thickness with increasing film thickness. The AFM lines scan spectra in Figure S4 show that the peak-to-peak surface roughness $\left(R_{\mathrm{pp}}\right)$ and RMS surface roughness $\left(R_{\mathrm{rms}}\right)$ increase with increasing film thickness $R_{\mathrm{pp}}$ from about $84 \mathrm{~nm}$ for the 1$\mu \mathrm{m}$-thick film to $293 \mathrm{~nm}$ for the $5-\mu \mathrm{m}$-thick film and $R_{\mathrm{rms}}$ from 8.6 to $72 \mathrm{~nm}$, respectively.

As can be seen from Figure 5, panels a2- $\mathfrak{2} 2$, many grains extend from the bottom of the film to the top and increase in diameter with increasing film thickness (grain length), while the smaller grains end at shorter lengths. The grain diameter $\left(d_{\mathrm{col}}\right)$ at the top surface for different thicknesses is tabulated in Table 2 and depicted in Figure S8a, as are the (average) growth rates $\left(R_{\mathrm{av}}\right)$ for the different thicknesses $(t)$. It is seen that $R_{\mathrm{av}}$ increases significantly with thickness. From the changing average growth rates, one can calculate the local growth rate at a given $z$-position in the film $(R(z))$; see the Supporting Information. Assuming that the amount of material per unit area per laser pulse does not change, this implies that the average void fraction of the film $\left(f_{\mathrm{v}, \mathrm{av}}(t)\right)$ as well as the local void fraction $f_{\mathrm{v}}(z)$ increase with thickness. This fits well with Thornton's Structure Zone Model. ${ }^{64}$ From Figure S8a, it is seen that the local growth rate peaks at $z \approx 3-4 \mu \mathrm{m}$. It follows that at this $z$-position in the film the void fraction is also largest (see Figure S8b). The SEM pictures and the XRD measurements indicate that the density of the grains does not change, but that the average spacing $(\delta)$ between the grains increases with thickness. The spacing changes from as little as $3 \mathrm{~nm}$ in the $0.5-1.0 \mu \mathrm{m} z$-range in the film to $29 \mathrm{~nm}$ for the $4-5 \mu \mathrm{m}$ film section, with a shallow maximum of $32 \mathrm{~nm}$ in the range 3$4 \mu \mathrm{m}$ (see Figure S $8 \mathrm{~b}$ ). It seems obvious that the increased spacing influences the physical properties of the film, because the clamping of the individual grains decreases with increasing grain spacing.

Ferroelectric, dielectric, and piezoelectric properties of the PZT films were measured as a function of thickness. Figure 6a shows the P-E hysteresis loops of the PZT films with different thicknesses. With increasing film thickness, the loop changes rapidly from the slanted loop, typically seen for a thin clamped dense film of PZT of MPB composition, to the square loop of a free crystal. Similar counter clockwise tilting of the $P-E$ loops with increasing film thickness was observed by Keech et al. ${ }^{22}$ in $350 \mathrm{~nm}$ PMN-PT capacitor structures narrowed in one lateral direction to an aspect ratio $t / w=0.03$ up to 1.85 . The counter clockwise rotation was attributed to the change in declamping and associated in-plane stress in the capacitor, causing changes in the domain wall mobility and an increased intrinsic response. The experimental $P_{\mathrm{r}}$ and $P_{\mathrm{s}}$ values increase and saturate for thicknesses above $3 \mu \mathrm{m}$. $P_{\mathrm{s}}$ saturates for large film thicknesses at a value of about $36.3 \mu \mathrm{C} \mathrm{cm} \mathrm{cm}^{-2}$ (Table 2). This is very close to the value $P_{\mathrm{s}}^{\mathrm{SC}} / \sqrt{2}$, where $P_{\mathrm{s}}^{\mathrm{SC}}=50 \mu \mathrm{C} \mathrm{cm}{ }^{-2}$ is the single-crystal value given by Haun et al. ${ }^{8}$ (Figure 6c). For the thinnest film, $P_{\mathrm{s}}$ is slightly less than $P_{s}^{S C} / \sqrt{3}$. Despite the fact that in XRD no changes in the out-of-plane measured lattice parameter are observed, the polarization change indicates that the strain state changes, because the value of the (out-of-plane) polarization is intimately connected with the crystal structure. It is commonly accepted that at the MPB, the polarization vector can easily rotate under the influence of small strain changes, which change the crystal symmetry. The observed trend in the polarization can be interpreted as being due to a gradual change of the crystal structure with changing clamping. However, we could not support the idea of changing crystal symmetry with XRD measurements, because it was not possible to determine the crystal structure accurately, because the reflection spots in reciprocal space maps are rather broad. On the other hand, 
Table 2. Properties of PZT Films Deposited at a Pulse Rate of $50 \mathrm{~Hz}$ as a Function of Film Thickness

\begin{tabular}{|c|c|c|c|c|c|c|c|c|c|}
\hline \multirow[b]{2}{*}{$\begin{array}{l}\text { thickness, } t \\
\quad(\mu \mathrm{m})\end{array}$} & \multirow[b]{2}{*}{$\begin{array}{l}\text { dep. rate } R_{\text {av }} \\
\left(\mathrm{nm} \text { pulse }{ }^{-1}\right)\end{array}$} & \multirow[b]{2}{*}{$\begin{array}{l}\underset{(\mathrm{nm})}{\operatorname{roughnes}} R_{\mathrm{pp}}, R_{\mathrm{rms}} \\
\end{array}$} & \multirow[b]{2}{*}{$\begin{array}{l}\text { column diameter } d_{\mathrm{col}} \\
(\mathrm{nm})^{a}\end{array}$} & \multirow[b]{2}{*}{$\begin{array}{c}\text { aspect ratio } \\
t / d_{\mathrm{col}}\end{array}$} & \multirow[b]{2}{*}{$\begin{array}{l}\text { ave void fraction } f_{\mathrm{v}, \mathrm{av}} \\
(\%)\end{array}$} & \multicolumn{2}{|c|}{$\left(\mu \mathrm{C} \mathrm{cm^{-2 } )}\right.$} & \multirow[b]{2}{*}{$\varepsilon_{\mathrm{r}, \max }^{\mathrm{LS} \quad b}$} & \multirow[b]{2}{*}{$\varepsilon_{\mathrm{r}}^{\mathrm{LS}}(0)^{b}$} \\
\hline & & & & & & $P_{\mathrm{r}}$ & $P_{\mathrm{s}}$ & & \\
\hline 0.5 & 0.0310 & $23 / 8.6$ & 55 & 9.1 & 2.0 & 17.3 & 27.7 & & 842 \\
\hline 1.0 & 0.0316 & $105 / 17.0$ & 110 & 9.1 & 3.9 & 26.8 & 32.5 & 1112 & 866 \\
\hline 2.0 & 0.0325 & $138 / 35.0$ & 145 & 13.8 & 6.9 & 32.9 & 36.3 & 1121 & 910 \\
\hline 3.0 & 0.0338 & $182 / 47.8$ & 155 & 19.4 & 11.2 & 33.3 & 36.3 & 1290 & 1048 \\
\hline 4.0 & 0.0354 & $216 / 61.2$ & 180 & 22.2 & 16.4 & 33.3 & 36.3 & 1520 & 1220 \\
\hline 5.0 & 0.0359 & $232 / 72.1$ & 225 & 22.2 & 18.1 & 31.6 & 36.3 & 1534 & 1252 \\
\hline
\end{tabular}

(a)

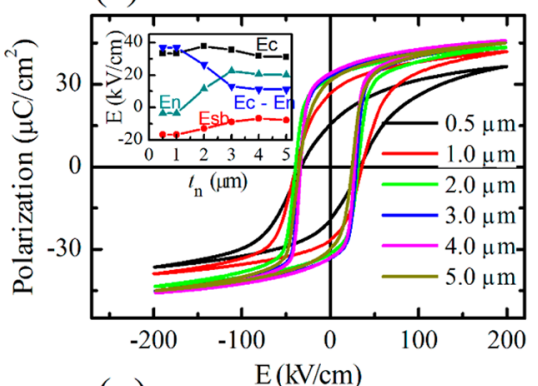

(c)

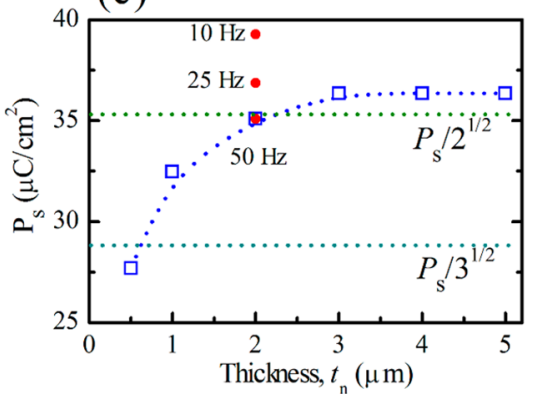

(b)

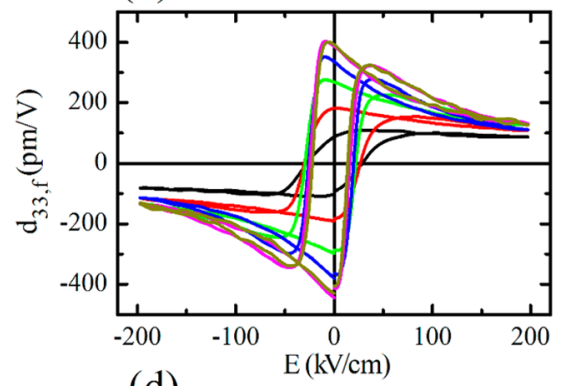

(d)

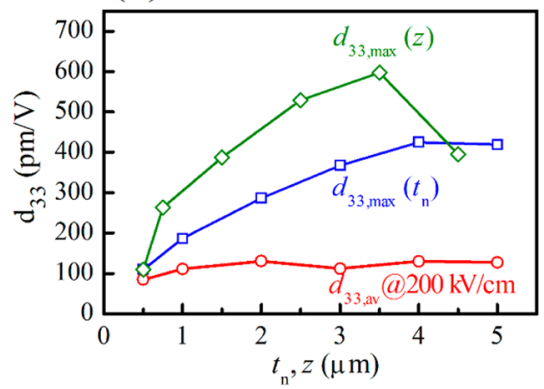

Figure 6. (a) $P-E$ and (b) $d_{33 f}-E$ loops of PZT films with various thicknesses deposited on Pt/Si at the pulse rate of $50 \mathrm{~Hz}$. (c) Measured saturation polarization as a function of film thickness and deposition rate. (d) High field value of the (small-signal) $d_{33 a v}(200)$, maximum value $d_{33 \text { max }}$ as a function of film thickness, and local maximum value $d_{33 \max }(z)$ as a function of position.

such broad spots can also be interpreted to be due to a spread in the lattice parameters, and thus to a gradual change of the lattice structure (and thus of the polarization orientation) along the length of the grains due to a changing strain state over the thickness of the grain.

The high-field slope $\left(\mathrm{dP} / \varepsilon_{0} \mathrm{~d} E\right)$ at $200 \mathrm{kV} \mathrm{cm}{ }^{-1}$, corresponding to the large-signal relative dielectric constant $\varepsilon_{\mathrm{r}}^{\mathrm{LS}}(200)$ (not to be confused with the small-signal relative dielectric constant obtained from $C-E$ curves), is for all $P-E$ loops approximately equal to 575 . The fact that $\varepsilon_{\mathrm{r}}^{\mathrm{LS}}(200)$ is approximately the same for all films, irrespective of the thickness, is taken as an indication that at high fields the complete film is in the same phase. In the above sketched picture, the film starts off in a phase with an orthorhombic or rhombohedral crystal symmetry at zero field, but becomes increasingly tetragonally distorted by the applied field, and the polarization is rotated out-of-plane. Note that $\varepsilon_{\mathrm{r}}^{\mathrm{LS}}(200)$ is fairly close to the zero-field single-crystal value $\varepsilon_{\mathrm{r}}^{\mathrm{LS}}(0)=382$ given by Haun et al. ${ }^{8}$ This indicates that at high fields the contribution from domain wall motion to $\varepsilon_{\mathrm{r}}^{\mathrm{LS}}(200)$ has become small and that the intrinsic effect of polarization rotation dominates the permittivity.

The capacitance-field $(C-E)$ curves are shown in Figure $\mathrm{S} 5 \mathrm{~b}$. At high field, the small-signal relative dielectric constants
$\left(\varepsilon_{\mathrm{r}}^{\mathrm{SS}}(200)\right)$ are approximately $260-300$ (at $200 \mathrm{kV} / \mathrm{cm}$ and slightly falling for larger fields strengths). These values are somewhat less than the zero-field, single domain, single-crystal value $\varepsilon_{\mathrm{r}}^{\mathrm{SC}}=382$ for the MPB composition, arising from polarization rotation only. Thus, $\varepsilon_{\mathrm{r}}^{\mathrm{SS}}(200)$ is likely due to a reduced polarization rotation at high fields. The difference from the higher high field value $\varepsilon_{\mathrm{r}}^{\mathrm{LS}}(200)$ indicates that for largesignal amplitude, the extrinsic effect of domain wall motion still contributes to the change in polarization, whereas for small signals the intrinsic effect of polarization rotation is dominant. The zero field and maximum values (occurring at "absolute" field values significantly less than $\left.E_{\mathrm{c}}\right) \varepsilon_{\mathrm{r}}^{\mathrm{SS}}(0)$ and $\varepsilon_{\mathrm{r}, \max }^{\mathrm{SS}}$ are a factor 3-5 larger (increasing with film thickness) than $\varepsilon_{\mathrm{r}}^{\mathrm{SS}}(200)$ and also much larger than $\varepsilon_{\mathrm{r}}^{\mathrm{SC}}(0)$. Thus, at low fields, domain wall motion and polarization reversal dominate low field $\varepsilon_{\mathrm{r}}^{\mathrm{SS}}$.

The $P-E$ and $C-E$ measurements point toward the presence of a polydomain structure in the films. Consider the depolarization energy of a grain that is spatially separated from its neighbors, as is to a good extent the case for films grown at high pulse rates and for larger thickness. Minimization of the depolarization energy over the outer surfaces of the grain requires that the grain is in a polydomain state of multiple domains, such that the net polarization normal to each of the side faces of the grain is zero. (The fine structure visible on 

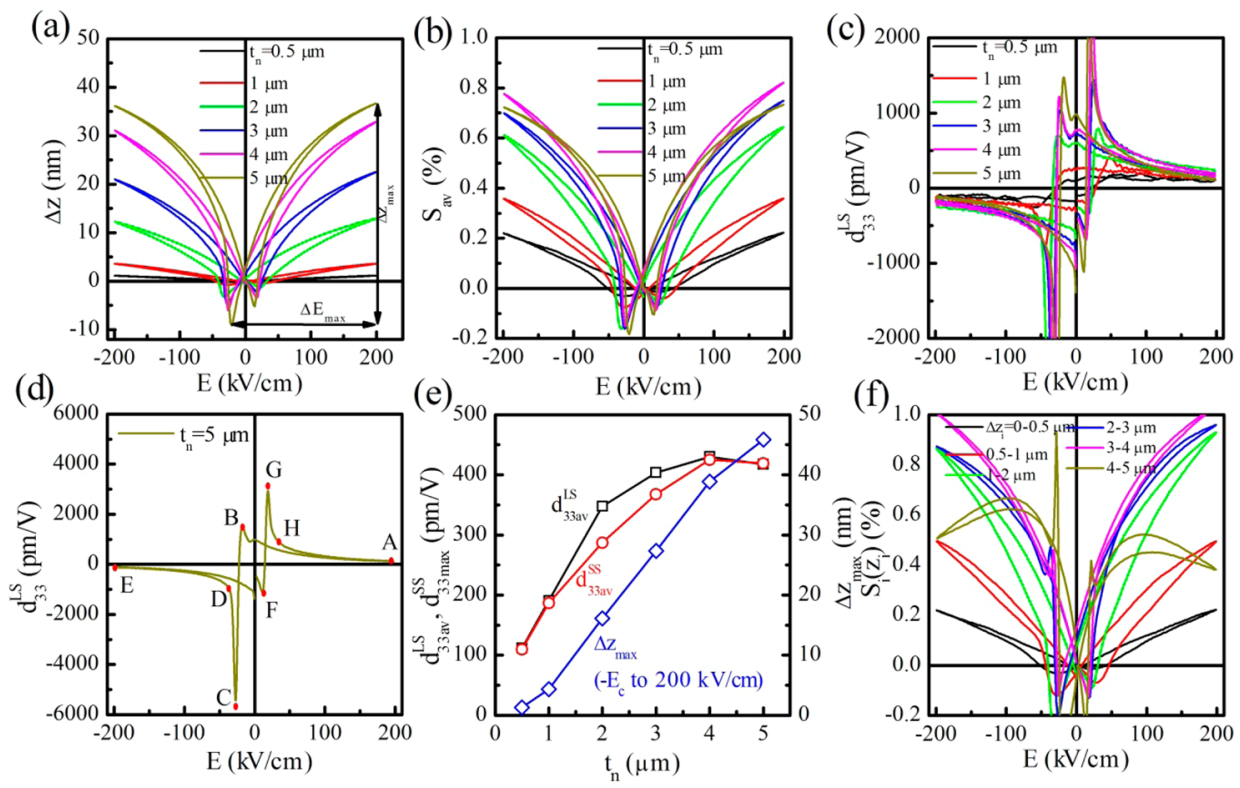

Figure 7. (a) Thickness increase of the PZT films deposited at $50 \mathrm{~Hz}$ as a function of the applied field; (b) strain as a function of the applied field; (c) large-signal piezoelectric coefficient, calculated from the strain; (d) large-signal piezoelectric coefficient of the $5 \mu \mathrm{m}$ PZT film deposited at $50 \mathrm{~Hz}$; and $(\mathrm{e}, \mathrm{f})$ strain in different thickness sections of the PZT films deposited at $50 \mathrm{~Hz}$.

most sides of the larger diameter grains (see Figure 5, panels $\mathrm{d} 3$, e3, and $\mathrm{f} 3$ ) might be a signature of this polarization domain structure.) This polydomain interpretation fits the picture sketched in the theoretical paper of Cao et al. ${ }^{26}$ where a poled single crystal of PZT with MPB composition is described by a polydomain phase consisting of four equivalent rhombohedral phases and one tetragonal phase. In the case of the thin films discussed here, consisting of (nearly) isolated long grains, the $P-E$ data suggest a polydomain phase consisting of rhombohedral-like domains changing to orthorhombic-like domains with increasing thickness and toward tetragonal-like domains at higher applied fields. As mentioned by Cao et al., ${ }^{26}$ it was already pointed out long ago by Isupov ${ }^{67,68}$ that a polydomain state is easier to switch than a single domain state, because a large number of available easy axis directions creates a low energy path for reorienting the polarization. As we have seen, such easy switching and domain wall motion contributes considerably to the permittivity of the films at low fields. We will see below that this has also a large effect on the piezoelectric properties.

The field dependence of the small-signal effective-longitudinal piezoelectric coefficients $\left(d_{33 \mathrm{f}}\left(t_{n}, E\right)\right)$ for the different film thicknesses $\left(t_{n}\right)$ is shown in Figure $6 \mathrm{~b}$. It is observed that for thicknesses larger than $0.5 \mu \mathrm{m}$, the hysteresis loop shows maxima in the rising and falling branches that increase with increasing thickness and saturate for thicknesses of $4 \mu \mathrm{m}$. In Figure $6 \mathrm{~d}$ is plotted the average of the absolute values of the measured extrema $d_{33 \max }\left(t_{n}\right)=\left(d_{33 \max }^{+}+\left|d_{33 \max }^{-}\right|\right) / 2$ as a function of the film thickness. $d_{33 \max }$ increases from about $100 \mathrm{pm} / \mathrm{V}$ for a thickness of $0.5 \mu \mathrm{m}$ to about $420 \mathrm{pm} \mathrm{V}^{-1}$ above $4 \mu \mathrm{m}$. (We expect that for thicknesses less than $0.5 \mu \mathrm{m}$, for which the density is largest, the piezoelectric coefficient does not change.) The average large field piezoelectric coefficient $d_{33 \text { av }}(E=200)=$ $\left(d_{33 \mathrm{f}}(200)+\left|d_{33 \mathrm{f}}(-200)\right|\right) / 2$ is approximately $86 \mathrm{pm} \mathrm{V}^{-1}$ for the thinnest films and $130 \mathrm{pm} \mathrm{V}^{-1}$ for the thicker films (Figure 6d). For the thinnest film the loop is slanted, whereas for the larger thicknesses the loops show near vertical switching branches, reflecting the decreasing degree of clamping with increasing film thickness. Using a procedure similar to that applied to deconvolute the thickness dependence of the growth rate, we determined the longitudinal piezoelectric coefficient at a given out-of-plane position in the film $d_{33 \max }\left(z_{i}\right)$ (Figure $6 \mathrm{~d}$ ). It is found that $d_{33 \max }\left(z_{i}\right)$ reaches a maximum in the thickness range $3-4 \mu \mathrm{m}$ as high as $600 \mathrm{pm} \mathrm{V}^{-1}$. This is in the same thickness range where the growth rate is largest, and thus where the grains are most separated. The highest $d_{33 \max }\left(z_{i}\right)$ value found in our films corresponds very well with the theoretical result from Cao et al. ( $525 \mathrm{pm} \mathrm{V}^{-1}$ for $x_{\mathrm{Ti}}=0.48$ and $725 \mathrm{pm}$ $\mathrm{V}^{-1}$ for $\left.x_{\mathrm{Ti}}=0.47\right),{ }^{26}$ and is much larger than the value for the single-crystal single-domain from Haun et al. ${ }^{8}$ They ascribed these very large values to easy domain wall motion in an unclamped polydomain single crystal.

Thus, we come to the following picture: the grains in the film can be considered to be polydomain, single crystals. With increasing thickness, the grains become less connected with neighboring grains, and the effect of clamping on domain wall motion, polarization rotation, and crystal unit cell deformation is reduced. The maximum $d_{33 \max }\left(z_{i}\right)$ in the thickness range 3-4 $\mu \mathrm{m}$ is close to the theoretical prediction of Cao et al. ${ }^{26}$ This suggests that at this position in the film the grains can be considered to be largely unclamped. For the thickest film, $d_{33 \max }\left(z_{i}\right)$ of the top micrometer of the film is decreased, suggesting that in this section the grains are slightly more connected again, causing more clamping. This corresponds with the reduced spacing between the grains in the 4-5 $\mu \mathrm{m}$ range as compared to the $3-4 \mu \mathrm{m}$ range (see Figure S8).

One expects that at high voltage bias all polarization is largely aligned in the field direction, and thus that domain wall motion does not contribute to the piezoelectric effect. In that case, the unit cell is already significantly tetragonally deformed by the field. Thus, one expects that $d_{33 \mathrm{av}}(200)$ is therefore largely determined by polarization extension and further tetragonal deformation of the unit cell. The experimentally determined values of $d_{33 a v}(200)$ as a function of film thickness (for the larger film thicknesses) are nearly equal, which supports the picture that the whole film is in the same (tetragonal) state. 
Table 3. Large- and Small-Signal Piezoelectric Coefficients as a Function of Film Thickness ${ }^{a}$

\begin{tabular}{|c|c|c|c|c|c|c|c|c|c|c|c|c|c|c|}
\hline $\begin{array}{c}t_{n} \\
(\mu \mathrm{m})\end{array}$ & $\begin{array}{c}d_{33}^{\mathrm{SS}}(0) \\
\left(\mathrm{pm} \mathrm{V}^{-1}\right)\end{array}$ & $\begin{array}{c}d_{33 \max }^{S S} \\
\left(\mathrm{pm} \mathrm{V}^{-1}\right)\end{array}$ & $\begin{array}{c}d_{33}^{\mathrm{SS}}(200) \\
\left(\mathrm{pm} \mathrm{V}^{-1}\right)\end{array}$ & $\begin{array}{c}d_{33}^{\mathrm{SS}}(i, j) \\
\left(\mathrm{pm} \mathrm{V}^{-1}\right)\end{array}$ & $\begin{array}{c}E_{\mathrm{p}}^{\prime} d_{31 \mathrm{f}}^{\prime}(\mathrm{GPa} \\
\left.\mathrm{pm} \mathrm{V} \mathrm{V}^{-1}\right)\end{array}$ & $\begin{array}{c}d_{33}^{\mathrm{LS}}(0) \\
\left(\mathrm{pm} \mathrm{V}^{-1}\right)\end{array}$ & $\begin{array}{c}d_{33 \max }^{S S} \\
\left(\mathrm{pm} \mathrm{V}^{-1}\right)\end{array}$ & $\begin{array}{l}d_{33}^{\mathrm{LS}}(200) \\
\left(\mathrm{pm} \mathrm{V}^{-1}\right)\end{array}$ & $\left(\begin{array}{c}d_{33 \mathrm{bi}}^{*} \\
\left(\mathrm{pm} \mathrm{V}^{-1}\right)\end{array}\right.$ & $\begin{array}{c}d_{33 \mathrm{bi}}^{*}(i, j) \\
\left(\mathrm{pm} \mathrm{V}^{-1}\right)\end{array}$ & $\begin{array}{c}d_{33 \text { uni }}^{*} \\
\left(\mathrm{pm} \mathrm{V}^{-1}\right)\end{array}$ & $\frac{d_{33 \max }^{\mathrm{LS}}}{d_{33 \max }^{S \mathrm{~S}}}$ & $\frac{d_{33}^{\mathrm{LS}}(0)}{d_{33}^{S S}(0)}$ & $\frac{d_{33}^{\mathrm{LS}}(200)}{d_{33}^{\mathrm{SS}}(200)}$ \\
\hline 0.5 & 88 & 110 & 86 & 110 & & 113 & 113 & 115 & 112 & 111 & 131 & $\begin{array}{c}c_{33 \max } \\
1.6\end{array}$ & 1.1 & 1.3 \\
\hline 1.0 & 183 & 186 & 111 & 264 & -8853 & 254 & 267 & 135 & 191 & 248 & 190 & 1.5 & 1.5 & 1.2 \\
\hline 2.0 & 269 & 305 & 130 & 387 & -9761 & 595 & 718 & 210 & 348 & 465 & 318 & 2.4 & 2.2 & 1.6 \\
\hline 3.0 & 338 & 354 & 112 & 529 & -9534 & 732 & 1048 & 185 & 404 & 480 & 359 & 3 & 2.1 & 1.7 \\
\hline 4.0 & 387 & 408 & 130 & 598 & -8399 & 768 & 1265 & 180 & 430 & 517 & 405 & 3.1 & 2 & 1.4 \\
\hline 5.0 & 394 & 405 & 127 & 395 & -7491 & 983 & 1495 & 110 & 417 & 465 & 383 & 3.7 & 2.5 & 0.9 \\
\hline
\end{tabular}

$a d_{33}^{S S}(0), d_{33 \max }^{S S} d_{33}^{S S}(200)$, and $d_{33}^{S S}(i, j)$ are the piezoelectric coefficients determined from the small-signal hysteresis loop measurements $($ Figure $6 \mathrm{~b})$ at $E=0$, the maximum value in the loop, the value at the maximum applied field $E=200 \mathrm{kV} \mathrm{cm}^{-1}$, and the value in the thickness section $(i, j)=\left(t_{n}, t_{n-1}\right)$, respectively. $d_{33}^{\mathrm{SS}}(0), d_{33 \max }^{\mathrm{LS}}$ and $d_{33}^{\mathrm{SS}}(200)$ are the equivalent values determined from the differentiated bipolar strain hysteresis loops (Figure $7 \mathrm{c}$ ). The $d_{33 \mathrm{bi}}^{*}$ and $d_{33 \mathrm{uni}}^{*}$ are the effective piezoelectric coefficients over the range from $-E_{\mathrm{c}}$ to $200 \mathrm{kV} \mathrm{cm}^{-1}$ and 0 to $200 \mathrm{kV} \mathrm{cm}^{-1}$, respectively, of the bipolar and unipolar strain hysteresis loops, determined as $d_{33}^{*}=\Delta S_{3} / \Delta E . d_{33 \mathrm{bi}}^{*}(i, j)$ is the effective piezoelectric coefficient of the thickness interval $(i, j)=$ $\left(t_{n}, t_{n-1}\right)$ over the range from $-E_{\mathrm{c}}$ to $200 \mathrm{kV} \mathrm{cm}{ }^{-1}$ of the bipolar strain hysteresis loop.

The piezoelectric response as discussed above was measured as the strain response to a relatively small amplitude AC voltage signal on a large DC bias. We expect that at small DC bias fields, only small oscillatory domain wall motions take place (which by many authors is observed to be hysteretic even for very low excitation fields), together with small polarization rotation and extension variations. The domain wall excursions are small and cyclic so that the domain wall structure in the grain averaged over many cycles of the small-signal AC measurement is static (except when switching occurs around the coercive field). Further, we expect that at large DC bias fields mainly polarization extension remains as the piezoelectric mechanism, because the unit cells are highly strained and therefore largely clamped by the field. This decreases the cyclic domain wall motion amplitude and the contribution of domain wall motion to the piezoelectric response. The situation is very different when the field bias is swept, as is done in displacement-electric field $(\Delta z-E$ or strain-field $S-E)$ measurements. In that case, the domain structure continuously changes at low fields, and domain walls continuously move through the grain.

Figure $7 \mathrm{a}$ shows the bipolar displacement hysteresis curves for the different thicknesses versus applied electric field $(\Delta z-$ $E)$ measured at $100 \mathrm{~Hz}$ and averaged over 100 cycles. Note that the maximum voltage is chosen such that for all films the same maximum field $\left( \pm 200 \mathrm{kV} \mathrm{cm}{ }^{-1}\right)$ is obtained. The strain-field hysteresis curves $S_{\mathrm{av}}\left(t_{n}, E\right)$ are depicted in Figure $7 \mathrm{~b}$. The loops show a strong increase of the strain with increasing thickness from about $0.2 \%$ at $200 \mathrm{kV} \mathrm{cm}{ }^{-1}$ for the $0.5-\mu \mathrm{m}$-thick film to nearly $0.8 \%$ for the thickest film. Unipolar strain measurements were performed (see Figure S12), and the normalized piezoelectric coefficient $d_{33}^{*}=S_{3}\left(E_{\max }\right) / E_{\max }$ and the maximum hysteresis $H=\max \left(\Delta S_{3}(E) / S_{3}(E)\right)$ were determined. All loops show significant hysteresis at all applied field values, indicating the contribution from domain wall motion and pinning to the piezoelectric activity.

From the strain hysteresis loops, the hysteresis loops of the large-signal piezoelectric coefficient $d_{33 \mathrm{f}}^{\mathrm{LS}}(E)=(\mathrm{d} \Delta z / \mathrm{d} V)_{E}$ are calculated (see Figure 7c). Extremely large values are obtained close to the coercive field, increasing with film thickness and reaching a largest value over $6000 \mathrm{pm} \mathrm{V}^{-1}$ for the $5 \mu \mathrm{m}$ film. However, these extreme values occur just after polarization reversal has taken place, and these parts of the loops $(B-C-D$, $\mathrm{F}-\mathrm{G}-\mathrm{H}$ in Figure $7 \mathrm{~d}$ ) cannot be used reversibly. These large "overshoots" arise from polarization switching from antiparallel to parallel to the applied field, inducing a large change (increase) in the strain (in the out-of-plane direction, accompanied by a large increase in the stress in the in-plane directions), while the domain structure does not adapt immediately to the new in-plane stress state. Only with changing applied field does the domain structure rearrange to minimize the stress energy. The sections $\mathrm{A}-\mathrm{B}$ and $\mathrm{E}-\mathrm{F}$ are reversible and can be used in static applications, and the $d_{33}^{\mathrm{LS}}(E)$ values on these branches are practically applicable. The zerofield $d_{33}^{\mathrm{LS}}(0)$ and maximum value $d_{33 \max }^{\mathrm{LS}}$ on the $\mathrm{E}-\mathrm{F}$ and $\mathrm{A}-\mathrm{B}$ branches as well as the value at $200 \mathrm{kV} \mathrm{cm}^{-1}$ are given in Table 3. Comparison with the values obtained from the average smallsignal hysteresis loops shows that the ratio of the large-signal to the small-signal zero field values increases with thickness from about 1.1 for the thinnest films to 2.5 for the thickest film, while the ratio for the maximum values increases from 1.6 to 3.7. The ratio of the high field values, on the other hand, does not show a clear trend and is relatively small around 1.4. The large increase of the large-signal piezoelectric coefficients of the thicker films as compared to the small-signal values is believed to be due to a larger contribution of domain wall motion and easier polarization rotation to the piezoelectricity in the case of LS measurements. As discussed above, the grains become less clamped with increasing thickness, so that domains can more easily move and the in-plane strain change due to polarization rotation is hampered less by clamping. This is corroborated further by the observation that at high field the increase of the ratio is much less because at high fields mainly polarization rotation and extension attributes to $d_{33}$.

For some applications, the static displacement and especially the maximum displacement range $\left|\Delta z_{\max }\right|$ is of importance. Figure $7 \mathrm{e}$ gives $\left|\Delta z_{\max }\right|$ as a function of the film thickness. The accessible range increases approximately linearly to about 41.7 $\mathrm{nm}$ for a voltage span $\left|\Delta V_{\max }\right|$ of $100 \mathrm{~V}$ for the 5- $\mu$ m-thick film. These films and especially the thicker films can be driven to significantly larger voltage and thus to somewhat larger maximum displacement values. However, from extending the displacement curves by curve fitting, we find that at $200 \mathrm{kV}$ $\mathrm{cm}^{-1}$ already about $90 \%$ of the $400 \mathrm{kV} \mathrm{cm}^{-1}$ displacement value is reached. The average piezoelectric coefficient over the maximum displacement range for $\left|E_{\max }\right|=200 \mathrm{kV} \mathrm{cm}^{-1}$, defined as $d_{33 \mathrm{av}}^{\mathrm{LS}}=\left|z_{\max }\right| /\left|V_{\max }\right|$, increases to about $400 \mathrm{pm} \mathrm{V}^{-1}$ for a thickness of $3 \mu \mathrm{m}$, slightly increases to $430 \mathrm{pm} \mathrm{V}^{-1}$ for the 4 $\mu \mathrm{m}$ thick film, and decreases then to $417 \mathrm{pm} \mathrm{V}^{-1}$ for the $5-\mu \mathrm{m}$ thick film (Figure 7e). Surprisingly, $d_{33 \mathrm{av}}^{\mathrm{LS}}$ is approximately equal to the maximum value obtained from the small-signal measurements, $d_{33 \max }^{\mathrm{SS}}$, for each thickness. We have no argument for this correspondence and think this is largely coincidental. Further, we note that the similar trends with thickness reflect 
the effect of decreasing clamping on both SS and LS piezoelectricity.

After deconvolution of the thickness dependence, one obtains the $z$-position-dependent strain-field hysteresis loops, $S\left(z_{i} E\right)$, as shown in Figure $7 f$. It is observed that the largest strain of $1.0 \%$ at $200 \mathrm{kV} \mathrm{cm}^{-1}$ occurs in the film section $3-4$ $\mu \mathrm{m}$. For the $2-3$ and 3-4 $\mu \mathrm{m}$ sections, the hysteresis is much smaller for $|E|>E_{\mathrm{c}}$ than for the bottom $2 \mu \mathrm{m}$. Further, the loops of these sections show overshoot, especially at the negative coercive field, as was also seen in the $d_{33}^{\mathrm{LS}}-E$ loops. The strain $S(2-3 \mu \mathrm{m})$ and $S(3-4 \mu \mathrm{m})$ jumps from a slightly negative value to a large positive value and then reduces again. This fits with the earlier explanation that in the unclamped sections of the grain the compressive (intrinsic) strain in the antiparallel polarization-field case goes over into tensile (intrinsic) strain when the polarization becomes parallel to the field. This highly strained state appears to relax, probably by domain wall motion and some polarization back rotation, to a less strained state. With increasing field $|E| \gg E_{\mathcal{c}}$ the strain increases further, but is increasingly determined by polarization rotation and less by domain wall motion. The fact that for negative coercive field (negative field corresponds to an applied field directed from the bottom to the top electrode) the overshoot is so large is taken as an indication that reverse domain growth is very fast. It is hypothesized that reverse domains nucleate at the top electrode, where the grains are widest. We think that the high growth rate of the reverse domains arises from the fact that grain boundaries, which may stop or slow lateral domain wall motion, are far apart, while for the reversal at positive field the nucleation starts at the bottom electrode interface, where all films have the same (small) grain diameter and thus the same limited lateral domain growth. At positive coercive field, one observes with increasing thickness increasingly steep switching, indicating that lateral domain growth also becomes easier with increasing grain size, but only for the thickest film is there a clear overshoot. For the top 4-5 $\mu \mathrm{m}$ of the film, the local strain reduces for fields increasing over about $|E|>100 \mathrm{kV} \mathrm{cm}^{-1}$. This implies that the thickness of the top layer is reduced with increasing field strength, which must be due to increasing tensile in-plane stress. This is again a signature of clamping in this part of the film.

Using the calculated $d_{33 \mathrm{av}}^{\mathrm{LS}}(E)$ hysteresis loops, one can again deconvolute the thickness dependence. Figure S11 shows the position-dependent $d_{33}^{\mathrm{LS}}\left(z_{i} E\right)$ hysteresis loops. The reversible sections $\mathrm{A}-\mathrm{B}$ and $\mathrm{E}-\mathrm{F}$ are given bold, while the remainder of the loops are given in gray. Extremely high values of $d_{33}^{\mathrm{LS}}(z, E)$ up to $3700 \mathrm{pm} \mathrm{V}^{-1}$ are found for the top $1 \mu \mathrm{m}$ thick layer of the 5 $\mu \mathrm{m}$ film. $d_{33}^{\mathrm{LS}}(4-5 \mu \mathrm{m}, E)$ not only switches sign near the coercive field but also at high field values $|E| \approx 100 \mathrm{kV} \mathrm{cm}^{-1}$. As we have seen above, this is because at high fields the top layer becomes thinner with increasing field. The latter effect does not occur for the layers underneath.

In Figure 8 are compared the results for the differently defined piezoelectric coefficients of the $5-\mu \mathrm{m}$-thick film, demonstrating the large differences between small- and largesignal measurements. The averaged small-signal measurement shows a relatively small change of the $d_{33 a v}^{\text {SS }}$-value, while the deduced loop for the 4-5 $\mu \mathrm{m}$ film section, $d_{33}^{\mathrm{SS}}(4-5 \mu \mathrm{m})$, differs from $d_{33 \mathrm{av}}^{\mathrm{SS}}$ in the overshoot during switching. Both $d_{33 \mathrm{av}}^{\mathrm{SS}}$ and $d_{33}^{\mathrm{SS}}(4-5 \mu \mathrm{m})$ have the same sign for larger fields $|E| \geq E_{\mathrm{c}}$. $d_{33 \mathrm{av}}^{\mathrm{LS}}$ is significantly larger than $d_{33 \text { av }}^{\text {SS }}$ for smaller fields and shows enormous overshoots during switching. $d_{33}^{\mathrm{LS}}(4-5 \mu \mathrm{m})$ reaches even larger values and shows the curious sign switch at about

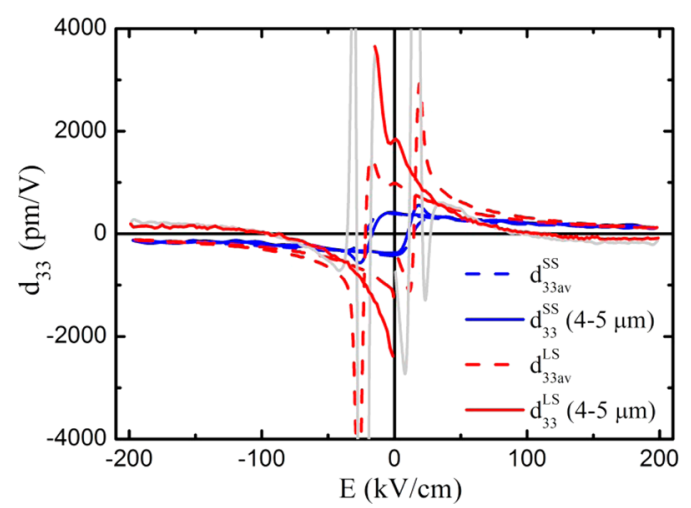

Figure 8. Comparison of piezoelectric coefficients of the 5- $\mu \mathrm{m}$-thick film and in the $4-5 \mu \mathrm{m}$ section, measured at large-signal and smallsignal piezoelectric loops.

$100 \mathrm{kV} \mathrm{cm}^{-1}$. All of these features were explained by the large contribution from fast domain wall motion in large-signal measurements as compared to small-signal measurements in which the contribution from polarization rotation to $d_{33}$ is relatively larger.

\section{CONCLUSIONS}

In summary, the electrical and mechanical properties of PZT films grown on $\mathrm{Pt} / \mathrm{Si}$ substrates strongly depend on the film microstructure. The deposition pulse rate is crucial for the columnar grain density, which determines the film clamping to the substrate and between individual grains, that in turn strongly influences the physical properties of the film. A high pulse rate favors a tapered grain shape structure and less densely packed columnar grains, leading to a higher $d_{33 \mathrm{f}}$ value (e.g., $305 \mathrm{pm} \mathrm{V}^{-1}$ for $2-\mu \mathrm{m}$-thick PZT films deposited at the pulse of $50 \mathrm{~Hz}$ ), whereas a denser columnar-like microstructure that is obtained with low pulse rates results in a higher remanent polarization and transversal piezoelectric coefficient. The film thickness significantly influences the film properties. The piezoelectric coefficients were found to be higher for PZT films with higher thicknesses. A maximum average $d_{33 \mathrm{f}}$ value of $408 \mathrm{pm} \mathrm{V}^{-1}$ was obtained in the $4-\mu \mathrm{m}$-thick PZT film (with laser pulse rate of $50 \mathrm{~Hz}$ ), whereas it was deduced that in the 3-4 $\mu \mathrm{m}$ section of thick films the local piezoelectric coefficient is as large as $600 \mathrm{pm} \mathrm{V}^{-1}$. Large-signal strain-field measurements demonstrate average strain values as large as $0.8 \%$ and locally up to $1.0 \%$ in thick films. These high values allow for maximum longitudinal displacements of over $40 \mathrm{~nm}$ for $5-\mu \mathrm{m}$ thick films. The enhanced piezoelectric coefficients of PZT films are explained in terms of changes in the microstructure, which allow for significantly less clamping of the lattice in the individual grains. This in turn allows for large changes in the domain structure with little domain wall pinning and easy polarization rotation over large angles. The huge piezoelectric and strain coefficients obtained in this study will open the way for a broad class of specific applications, such as in a nanocontrol system based on piezoelectric actuators for the control of optical cavities.

\section{ASSOCIATED CONTENT}

S Supporting Information

The Supporting Information is available free of charge on the ACS Publications website at DOI: 10.1021/acsami.6b16470. 
XRD patterns; height profiles; cross-sectional SEM images; AFM surface height profiles; dielectric constant-electric field curves; schematic of the surface micromachining process; three-dimensional scanning image; measured average growth rate, rms roughness, and grain diameter; average growth rate and grain diameter; maximum measured value of the small-signal longitudinal piezoelectric coefficient; large-signal piezoelectric coefficient; parameters used for calculating the piezoelectric coefficient; and unipolar strain-field measurements $(\mathrm{PDF})$

\section{AUTHOR INFORMATION}

\section{Corresponding Author}

*E-mail: d.m.nguyen@utwente.nl.

\section{ORCID $\odot$}

Minh D. Nguyen: 0000-0001-9725-4004

\section{Notes}

The authors declare no competing financial interest.

\section{ACKNOWLEDGMENTS}

This research was supported by the project number M62.3.10404 in the framework of the Research Program of the Materials innovation institute (M2i) (www.m2i.nl) and by the NanoNextNL-a micro and nanotechnology consortium of the Government of The Netherlands and 130 partners. We thank M. Smithers for performing the HRSEM experiments.

\section{REFERENCES}

(1) Eom, C. B.; Trolier-McKinstry, S. Thin-Film Piezoelectric MEMS. MRS Bull. 2012, 37, 1007-1017.

(2) Smith, G. L.; Pulskamp, J. S.; Sanchez, L. M.; Potrepka, D. M.; Proie, R. M.; Ivanov, T. G.; Rudy, R. Q.; Nothwang, W. D.; Bedair, S. S.; Meyer, C. D.; Polcawich, R. G. PZT-Based Piezoelectric MEMS Technology. J. Am. Ceram. Soc. 2012, 95, 1777-1792.

(3) Iijima, T.; Osone, S.; Shimojo, Y.; Nagai, H. Synthesis of $10-\mu \mathrm{m}-$ Thick Lead Zirconate Titanate Films on 2-in. Si Substrates for Piezoelectric Film Devices. Int. J. Appl. Ceram. Technol. 2006, 3, 442447.

(4) Kanda, K.; Kanno, I.; Kotera, H.; Wasa, K. Simple Fabrication of Metal-Based Piezoelectric MEMS by Direct Deposition of $\mathrm{Pb}(\mathrm{Zr}, \mathrm{Ti})$ $\mathrm{O}_{3}$ Thin Films on Titanium Substrates. J. Microelectromech. Syst. 2009, $18,610-615$.

(5) Muralt, P. Recent Progress in Materials Issues for Piezoelectric MEMS. J. Am. Ceram. Soc. 2008, 91, 1385-1396.

(6) Jaffe, B.; Cook, W. R., Jr.; Jaffe, H. Piezoelectric Ceramics; Academic Press Inc.: London, 1971.

(7) Torah, R. N.; Beeby, S. P.; White, N. M. Experimental Investigation into the Effect of Substrate Clamping on the Piezoelectric Behaviour of Thick-Film PZT Elements. J. Phys. D: Appl. Phys. 2004, 37, 1074-1078.

(8) Haun, M. J.; Furman, E.; Jang, S. J.; Cross, L. E. Thermodynamic Theory of the Lead Zirconate-Titanate Solid Solution System, Part V: Theoretical Calculations. Ferroelectrics 1989, 99, 63-86.

(9) Du, X.; Belegundu, U.; Uchino, K. Crystal Orientation Dependence of Piezoelectric Properties in Lead Zirconate Titanate: Theoretical Expectation for Thin Films. Jpn. J. Appl. Phys. 1997, 36, $5580-5587$.

(10) Du, X.; Zheng, J.; Belegundu, U.; Uchino, K. Crystal Orientation Dependence of Piezoelectric Properties of Lead Zirconate Titanate near the Morphotropic Phase Boundary. Appl. Phys. Lett. 1998, 72, 2421-2423.

(11) Ouyang, J.; Yang, S. Y.; Chen, L.; Ramesh, R.; Roytburd, A. L. Orientation Dependence of the Converse Piezoelectric Constants for
Epitaxial Single Domain Ferroelectric Films. Appl. Phys. Lett. 2004, 85, 278-280

(12) Damjanovic, D. Contributions to the Piezoelectric Effect in Ferroelectric Single Crystals and Ceramics. J. Am. Ceram. Soc. 2005, $88,2663-2676$

(13) Bassiri-Gharb, N.; Fujii, I.; Hong, E.; Trolier-McKinstry, S.; Taylor, D. V.; Damjanovic, D. Domain Wall Contributions to the Properties of Piezoelectric Thin Films. J. Electroceram. 2007, 19, 4967.

(14) Pertsev, N. A.; Kukhar, V. G.; Kohlstedt, H.; Waser, R. Phase Diagrams and Physical Properties of Single-Domain Epitaxial $\mathrm{Pb}$ $\left(\mathrm{Zr}_{1-\mathrm{x}} \mathrm{Ti}_{\mathrm{x}}\right) \mathrm{O}_{3}$ Thin Films. Phys. Rev. B: Condens. Matter Mater. Phys. 2003, 67, 054107.

(15) Koukhar, V. G.; Pertsev, N. A.; Waser, R. Thermodynamic Theory of Epitaxial Ferroelectric Thin Films with Dense Domain Structures. Phys. Rev. B: Condens. Matter Mater. Phys. 2001, 64, 214103.

(16) Kukhar, V. G.; Pertsev, N. A.; Kohlstedt, H.; Waser, R. Polarization States of Polydomain Epitaxial $\mathrm{Pb}\left(\mathrm{Zr}_{1-\mathrm{x}} \mathrm{Ti}_{\mathrm{x}}\right) \mathrm{O}_{3}$ Thin Films and Their Dielectric Properties. Phys. Rev. B: Condens. Matter Mater. Phys. 2006, 73, 214103.

(17) Houwman, E. P.; Vergeer, K.; Koster, G.; Rijnders, G. In Correlated Functional Oxides - Nanocomposites and Heterostructures; Nishikawa, H., Iwata, N., Endo, T., Takamura, Y., Lee, G.-H., Mele, P., Eds.; Springer International Publishing AG: Switzerland, 2017; Chapter 2, pp 29-53.

(18) Vergeer, K. Structure and Functional Properties of Epitaxial $\mathrm{PbZr}_{x} \mathrm{Ti}_{1-x} \mathrm{O}_{3}$ Films. Ph.D. Thesis, University of Twente, Enschede, The Netherlands, 2017.

(19) Nagarajan, V.; Stanishevsky, A.; Chen, L.; Zhao, T.; Liu, B.-T.; Melngailis, J.; Roytburd, A. L.; Ramesh, R.; Finder, J.; Yu, Z.; Droopad, R. Eisenbeiser, K. Realizing Intrinsic Piezoresponse in Epitaxial Submicron Lead Zirconate Titanate Capacitors on Si. Appl. Phys. Lett. 2002, 81, 4215-4217.

(20) Stanishevsky, A.; Aggarwal, S.; Prakash, A. S.; Melngailis, J.; Ramesh, R. Focused Ion-Beam Patterning of Nanoscale Ferroelectric Capacitors. J. Vac. Sci. Technol., B: Microelectron. Process. Phenom. 1998, 16, 3899-3902.

(21) Ganpule, C. S.; Stanishevsky, A.; Aggarwal, S.; Melngailis, J.; Williams, E.; Ramesh, R.; Joshi, V.; Paz de Araujo, C. Scaling of Ferroelectric and Piezoelectric Properties in $\mathrm{Pt} / \mathrm{SrBi}_{2} \mathrm{Ta}_{2} \mathrm{O}_{9} / \mathrm{Pt}$ Thin Films. Appl. Phys. Lett. 1999, 75, 3874-3876.

(22) Keech, K.; Shetty, S.; Kuroda, M. A.; Liu, X. H.; Martyna, G. J.; Newns, D. M.; Trolier-McKinstry, S. Lateral Scaling of $\mathrm{Pb}$ $\left(\mathrm{Mg}_{1 / 3} \mathrm{Nb}_{2 / 3}\right) \mathrm{O}_{3}-\mathrm{PbTiO}_{3}$ Thin Films for Piezoelectric Logic Applications. J. Appl. Phys. 2014, 115, 234106.

(23) Bühlmann, S.; Dwir, B.; Baborowski, J.; Muralt, P. Size Effect in Mesoscopic Epitaxial Ferroelectric Structures: Increase of Piezoelectric Response with Decreasing Feature Size. Appl. Phys. Lett. 2002, 80, 3195-3197.

(24) Li, J.-H.; Chen, L.; Nagarajan, V.; Ramesh, R.; Roytburd, A. L. Finite Element Modeling of Piezoresponse in Nanostructured Ferroelectric Films. Appl. Phys. Lett. 2004, 84, 2626-2628.

(25) Kim, D. M.; Eom, C. B.; Nagarajan, V.; Ouyang, J.; Ramesh, R.; Vaithyanathan, V.; Schlom, D. G. Thickness Dependence of Structural and Piezoelectric Properties of Epitaxial $\mathrm{Pb}\left(\mathrm{Zr}_{0.52} \mathrm{Ti}_{0.48}\right) \mathrm{O}_{3}$ Films on $\mathrm{Si}$ and $\mathrm{SrTiO}_{3}$ Substrates. Appl. Phys. Lett. 2006, 88, 142904.

(26) Cao, Y.; Sheng, G.; Zhang, J. X.; Choudhury, S.; Li, Y. L.; Randall, C. A.; Chen, L. Q. Piezoelectric Response of Single-Crystal $\mathrm{PbZr}_{1-\mathrm{x}} \mathrm{Ti}_{\mathrm{x}} \mathrm{O}_{3}$ near Morphotropic Phase Boundary Predicted by PhaseField Simulation. Appl. Phys. Lett. 2010, 97, 252904.

(27) Hata, T.; Kawagoe, S.; Zhang, W.; Sasaki, K.; Yoshioka, Y. Proposal of New Mixture Target for PZT Thin Films by Reactive Sputtering. Vacuum 1998, 51, 665-671.

(28) Wang, C.; Kryder, M. H. Low Fatigue in Epitaxial $\mathrm{Pb}\left(\mathrm{Zr}_{0.2} \mathrm{Ti}_{0.8}\right) \mathrm{O}_{3}$ on $\mathrm{Si}$ Substrates with $\mathrm{LaNiO}_{3}$ Electrodes by $\mathrm{RF}$ Sputtering. J. Electron. Mater. 2009, 38, 1921-1925.

(29) Bouregba, R.; Sama, N.; Soyer, C.; Remiens, D. Analysis of Size Effects in $\mathrm{Pb}\left(\mathrm{Zr}_{0.54} \mathrm{Ti}_{0.46}\right) \mathrm{O}_{3}$ Thin Film Capacitors with Platinum and 
$\mathrm{LaNiO}_{3}$ Conducting Oxide Electrodes. J. Appl. Phys. 2009, 106, 044101.

(30) Yu, T.; Chen, Y.-F.; Liu, Z.-G.; Xiong, S.-B.; Sun, L.; Chen, X.Y.; Shi, L.-J.; Ming, N.-B. Epitaxial $\mathrm{Pb}\left(\mathrm{Zr}_{0.53} \mathrm{Ti}_{0.47}\right) \mathrm{O}_{3} / \mathrm{LaNiO}_{3}$ Heterostructures on Single Crystal Substrates. Appl. Phys. Lett. 1996, 69, 2092-2094.

(31) Morita, T.; Wagatsuma, Y.; Cho, Y.; Morioka, H.; Funakubo, H.; Setter, N. Ferroelectric Properties of an Epitaxial Lead Zirconate Titanate Thin Film Deposited by a Hydrothermal Method Below the Curie Temperature. Appl. Phys. Lett. 2004, 84, 5094-5096.

(32) Feigl, L.; Zheng, S. J.; Birajdar, B. I.; Rodriguez, B. J.; Zhu, Y. L.; Alexe, M.; Hesse, D. Impact of High Interface Density on Ferroelectric and Structural Properties of $\mathrm{PbZr}_{0.2} \mathrm{Ti}_{0.8} \mathrm{O}_{3} / \mathrm{PbZr}_{0.4} \mathrm{Ti}_{0.6} \mathrm{O}_{3}$ Epitaxial Multilayers. J. Phys. D: Appl. Phys. 2009, 42, 085305.

(33) Walker, D.; Thomas, P. A.; Collins, S. P. A Comprehensive Investigation of the Structural Properties of Ferroelectric $\mathrm{PbZr}_{0.2} \mathrm{Ti}_{0.8} \mathrm{O}_{3}$ Thin Films Grown by PLD. Phys. Status Solidi $A$ 2009, 206, 1799-1803.

(34) Anderson, P. S.; Guerin, S.; Hayden, B. E.; Han, Y.; Pasha, M.; Whittle, K. R; Reaney, I. M. Optimization of Synthesis of the Solid Solution, $\mathrm{Pb}\left(\mathrm{Zr}_{1-\mathrm{x}} \mathrm{Ti}_{\mathrm{x}}\right) \mathrm{O}_{3}$ on a Single Substrate Using a HighThroughput Modified Molecular-Beam Epitaxy Technique. J. Mater. Res. 2009, 24, 164-172.

(35) Tokumitsu, E.; Ueno, S.; Nakamura, R.-I.; Ishiwara, H. Characterization of $\mathrm{Pb}\left(\mathrm{Zr}_{\mathrm{x}} \mathrm{Ti}_{1-\mathrm{x}}\right) \mathrm{O}_{3}$ Films Prepared by Vacuum Evaporation Method. Integr. Ferroelectr. 1995, 7, 215-223.

(36) Park, B.-E.; Shouriki, S.; Tokumitsu, E.; Ishiwara, H. Fabrication of $\mathrm{PbZr}_{\mathrm{x}} \mathrm{Ti}_{1-\mathrm{x}} \mathrm{O}_{3}$ Films on Si Structures Using $\mathrm{Y}_{2} \mathrm{O}_{3}$ Buffer Layers. Jpn. J. Appl. Phys. 1998, 37, 5145-5149.

(37) Pan, C.-Y.; Chen, Y.-L.; Tsai, D.-S. Synthesis and Properties of Lead Zirconate Titanate Thin Films via Metalorganic Chemical Vapor Deposition. J. Mater. Res. 2002, 17, 1536-1542.

(38) Otani, Y.; Okamura, S.; Shiosaki, T. Recent Developments on MOCVD of Ferroelectric Thin Films. J. Electroceram. 2004, 13, 15-22.

(39) Lee, H.-C.; Lee, W.-J. Characterization of $\mathrm{Pb}(\mathrm{Zr}, \mathrm{Ti}) \mathrm{O}_{3}$ Thin Films Fabricated by Plasma Enhanced Chemical Vapor Deposition on Ir-Based Electrodes. J. Vac. Sci. Technol., A 2002, 20, 1939-1947.

(40) Lee, H.-C.; Lee, W.-J. Preparation and Characterization of $\mathrm{Pb}(\mathrm{Zr}, \mathrm{Ti}) \mathrm{O}_{3}$ Films Deposited on $\mathrm{Pt} / \mathrm{RuO}_{2}$ Hybrid Electrode for Ferroelectric Random Access Memory Devices. Jpn. J. Appl. Phys. 2001, 40, 6566-6573.

(41) Hsu, Y.-C.; Wu, C.-C.; Lee, C.-C.; Cao, G. Z.; Shen, I. Y. Demonstration and Characterization of PZT Thin-Film Sensors and Actuators for Meso- and Micro-structures. Sens. Actuators, A 2004, 116, 369-377.

(42) Han, H.; Zhong, J.; Kotru, S.; Padmini, P.; Song, X. Y.; Pandey, R. K. Improved Ferroelectric Property of $\mathrm{LaNiO}_{3} / \mathrm{Pb}\left(\mathrm{Zr}_{0.2} \mathrm{Ti}_{0.8}\right) \mathrm{O}_{3} /$ $\mathrm{LaNiO}_{3}$ Capacitors Prepared by Chemical Solution Deposition on Platinized Silicon. Appl. Phys. Lett. 2006, 88, 092902.

(43) Bhaskar, A.; Chang, T.-H.; Chang, H.-Y.; Cheng, S.-Y. $\mathrm{Pb}\left(\mathrm{Zr}_{0.53} \mathrm{Ti}_{0.47}\right) \mathrm{O}_{3}$ Thin Films with Different Thicknesses Obtained at Low Temperature by Microwave Irradiation. Appl. Surf. Sci. 2009, 255, 3795-3800.

(44) Vu, H. N.; Le, M. V.; Bui, H. T.; Nguyen, M. D. Improvement of Electrical Property for $\mathrm{Pb}\left(\mathrm{Zr}_{0.53} \mathrm{Ti}_{0.47}\right) \mathrm{O}_{3}$ Ferroelectric Thin Film Deposited by Sol-Gel Method on SRO Electrode. J. Phys.: Conf. Ser. 2009, 187, 012063.

(45) Schneller, T.; Waser, R. Chemical Modifications of Pb$\left(\mathrm{Zr}_{0.3}, \mathrm{Ti}_{0.7}\right) \mathrm{O}_{3}$ Precursor Solutions and Their Influence on the Morphological and Electrical Properties of the Resulting Thin Films. J. Sol-Gel Sci. Technol. 2007, 42, 337-352.

(46) Zhu, T. J.; Lu, L.; Lai, M. O. Pulsed Laser Deposition of LeadZirconate-Titanate Thin Films and Multilayered Heterostructures. Appl. Phys. A: Mater. Sci. Process. 2005, 81, 701-714.

(47) Jelínek, M.; Trtík, V.; Jastrabík, L. In Physics and Materials Science of High Temperature Superconductors, IV; Kossowsky, M. J. R., Novak, J., Eds.; Springer: Netherlands, Dordrecht, 1997; pp 215-231.
(48) Nguyen, M. D.; Vu, H. N.; Blank, D. H. A.; Rijnders, G. Epitaxial $\mathrm{Pb}(\mathrm{Zr}, \mathrm{Ti}) \mathrm{O}_{3}$ Thin Films for a MEMS Application. Adv. Nat. Sci.: Nanosci. Nanotechnol. 2011, 2, 015005.

(49) Tyunina, M.; Leppävuori, S. Effects of Laser Fluence, Size, and Shape of the Laser Focal Spot in Pulsed Laser Deposition Using a Multielemental Target. J. Appl. Phys. 2000, 87, 8132-8142.

(50) Guan, L.; Zhang, D. M.; Li, X.; Li, Z. H. Role of Pulse Repetition Rate in Film Growth of Pulsed Laser Deposition. Nucl. Instrum. Methods Phys. Res., Sect. B 2008, 266, 57-62.

(51) Corkovic, S.; Zhang, Q.; Whatmore, R. W. The Investigation of Key Processing Parameters in Fabrication of $\mathrm{Pb}\left(\mathrm{Zr}_{\mathrm{x}} \mathrm{Ti}_{1-\mathrm{x}}\right) \mathrm{O}_{3}$ Thick Films for MEMS Applications. J. Electroceram. 2007, 19, 295-301.

(52) Galca, A. C.; Stancu, V.; Husanu, M. A.; Dragoi, C.; Gheorghe, N. G.; Trupina, L.; Enculescu, M.; Vasile, E. Substrate-Target Distance Dependence of Structural and Optical Properties in Case of $\mathrm{Pb}(\mathrm{Zr}, \mathrm{Ti}) \mathrm{O}_{3}$ Films Obtained by Pulsed Laser Deposition. Appl. Surf. Sci. 2011, 257, 5938-5943.

(53) Pham, M. T. N.; Boukamp, B. A.; Rijnders, G.; Bouwmeester, H. J. M.; Blank, D. H. A. Pulsed Laser Deposition of PZT/Pt Composite Thin Films with High Dielectric Constants. Appl. Phys. A: Mater. Sci. Process. 2004, 79, 907-910.

(54) Dale, D.; Fleet, A.; Suzuki, Y.; Brock, J. D. X-ray Scattering from Real Surfaces: Discrete and Continuous Components of Roughness. Phys. Rev. B: Condens. Matter Mater. Phys. 2006, 74, 085419.

(55) Blank, D. H. A.; Dekkers, M.; Rijnders, G. Pulsed Laser Deposition in Twente: from Research Tool towards Industrial Deposition. J. Phys. D: Appl. Phys. 2014, 47, 034006.

(56) Salvadori, M. C.; Brown, I. G.; Vaz, A. R.; Melo, L. L.; Cattani, M. Measurement of the Elastic Modulus of Nanostructured Gold and Platinum Thin Films. Phys. Rev. B: Condens. Matter Mater. Phys. 2003, 67, 153404.

(57) Prume, K.; Muralt, P.; Calame, F.; Schmitz-Kempen, T.; Tiedke, S. Extensive Electromechanical Characterization of PZT Thin Films for MEMS Applications by Electrical and Mechanical Excitation Signals. J. Electroceram. 2007, 19, 407-411.

(58) Prume, K.; Muralt, P.; Calame, F.; Schmitz-Kempen, T.; Tiedke, S. Piezoelectric Thin Films: Evaluation of Electrical and Electromechanical Characteristics for MEMS Devices. IEEE Trans. Ultrason. Ferroelectr. Freq. Control 2005, 10, 8-14.

(59) The transverse piezoelectric coefficient $e_{31 \mathrm{f}}$ can be determined directly from a four-point bending experiment by measuring the induced charge as a function of the imposed strain. This has the large advantage that one obtains directly a value for $e_{31 \mathrm{f}}$ without the need of knowledge of the elastic properties of the film. However, the aixACCT four-point bending system requires relatively large specially made samples, which were not present in the mask sets available to us. Instead, we estimated thickness averaged values of the product of the (in-plane) Young's modulus $E_{\mathrm{p}}$ and the transverse piezoelectric coefficient, $\left\langle E_{\mathrm{p}} d_{31 \mathrm{f}}\right\rangle$, from the tip displacement of cantilever structures under an applied voltage across the piezoelectric capacitor on top of the Si cantilever beam (see the Supporting Information).

(60) Nguyen, M. D.; Dekkers, M.; Vu, H. N.; Rijnders, G. FilmThickness and Composition Dependence of Epitaxial Thin-Film PZTBased Mass-Sensors. Sens. Actuators, A 2013, 199, 98-105.

(61) Noheda, B.; Gonzalo, J. A.; Cross, L. E.; Guo, R.; Park, S.-E.; Cox, D. E.; Shirane, G. Tetragonal-to-Monoclinic Phase Transition in a Ferroelectric Perovskite: The Structure of $\mathrm{PbZr}_{0.52} \mathrm{Ti}_{0.48} \mathrm{O}_{3}$. Phys. Rev. B: Condens. Matter Mater. Phys. 2000, 61, 8687-8695.

(62) Wang, Y. U. Diffraction Theory of Nanotwin Superlattices with Low Symmetry Phase: Application to Rhombohedral Nanotwins and Monoclinic MA and MB Phases. Phys. Rev. B: Condens. Matter Mater. Phys. 2007, 76, 024108.

(63) Jin, Y. M.; Wang, Y. U.; Khachaturyan, A. G.; Li, J. F.; Viehland, D. Adaptive Ferroelectric States in Systems with Low Domain Wall Energy: Tetragonal Microdomains. J. Appl. Phys. 2003, 94, 36293640.

(64) Thornton, J. A. Structure-Zone Models of Thin Films. Proc. SPIE 1986, 95. 
(65) Rijnders, G.; Blank, D. H. A. In Growth Kinetics During Pulsed Laser Deposition in Pulsed Laser Deposition of Thin Films: ApplicationsLed Growth of Functional Materials; Eason, R., Ed.; John Wiley \& Sons, Inc.: Hoboken, NJ, 2006; Chapter 4, pp 85-97.

(66) The decreasing out-of-plane polarization is here explained in terms of a rotation of the macroscopic polarization vector into the film plane. On microscopic scale, such a rotation may arise from a changing $c$-domain fraction of a film with the $c / a$ domain structure under the influence of strain or applied field, as well as a real rotation of the polarization vector in the individual unit cells.

(67) Isupov, $\mathrm{V}$. A. Properties of $\mathrm{Pb}(\mathrm{Ti}, \mathrm{Zr}) \mathrm{O}_{3}$ Piezoelectric Ceramics and Nature of Their Orientational Dielectric Polarization. Sov. Phys. Solid State 1968, 10, 989-991.

(68) Isupov, V. A. Some Aspects of the Physics of Piezoelectric Ceramics. Ferroelectrics 1983, 46, 217-225. 